SÁnCHEZ HernándeZ, A. "Consideraciones sobre la reforma de la legislación civil en materia de discapacidad: de la incapacitación al apoyo", REDUR 19, diciembre 2021, págs. 23-55. ISSN 1695-078X. http://doi.org/10.18172/redur.5318

\title{
CONSIDERACIONES SOBRE LA REFORMA DE LA LEGISLACIÓN CIVIL EN MATERIA DE DISCAPACIDAD: DE LA INCAPACITACIÓN AL APOYO
}

\author{
PROF. DR. ÁNGEL SÁNCHEZ HERNÁNDEZ \\ CATEDRÁTICO DE DERECHO CIVIL \\ UNIVERSIDAD DE LA RIOJA \\ ACADÉMICO CORRESPONDIENTE DE LA REAL ACADEMIA DE DOCTORES DE ESPAÑA Y DE LA \\ REAL ACADEMIA DE JURISPRUDENCIA Y LEGISLACIÓN DE ESPAÑA \\ angel.sanchez@unirioja.es
}

SUMARIO: I. CONSIDERACIONES JURÍDICAS GENERALES EN TORNO A LA PERSONA Y A LA CAPACIDAD DE LA PERSONA. II. LA CONVENCIÓN SOBRE LOS DERECHOS DE LAS PERSONAS CON DISCAPACIDAD, DE 13 DE DICIEMBRE DE 2006. II.1. EL ART. 12 DE LA CONVENCIÓN A LA LUZ DE LAS OBSERVACIONES DEL COMITÉ SOBRE loS DERECHOS DE LAS PERSONAS CON DiSCAPACIDAD. II.2. El ART. 12 DE LA CONVENCIÓN DE 2006 Y LA CAPACIDAD DE LA PERSONA CON DISCAPACIDAD. II.3. LA PERMANENCIA DE LA TEORÍA CLÁSICA DE LA CAPACIDAD DE LA PERSONA. II.4. LA UNIFICACIÓN DE LA CAPACIDAD DE LA PERSONA TRAS LA CONVENCIÓN DE 2006. II.5. LA INCIDENCIA DEL ARTÍCULO 12 DE LA CONVENCIÓN DE 2006 EN LA TEORÍA CLÁSICA DE LA CAPACIDAD DE LA PERSONA SEGÚN LA JURISPRUDENCIA DEL T.S. II.6. CONCLUSIONES SOBRE LAS POSICIONES DOCTRINALES Y LA POSTURA DE LA JURISPRUDENCIA. III. EL CAMBIO DE SISTEMA DE PROTECCIÓN DE LA DISCAPACIDAD INTELECTUAL EN NUESTRO CÓDIGO CIVIL. IV. BIBLIOGRAFÍA

RESUMEN: La reforma de la legislación civil para el apoyo a las personas con discapacidad en el ejercicio de su capacidad jurídica (Ley 8/2021, de 2 de junio), busca la adaptación a la Convención de Nueva York de 2006 para facilitar la toma de las propias decisiones de esas personas mediante un modelo de apoyos. No se trata de que el tercero que apoya sustituya a la persona con discapacidad intelectual, sino de que aquel ponga a disposición de ésta los apoyos precisos para que pueda tomar sus propias decisiones, recuperando su protagonismo en la toma de decisiones que le afectan, como protagonista activo en el desarrollo de su proyecto vital. La intervención del tercero que apoya no es para sustituir a la persona con discapacidad intelectual en la toma de decisiones, sino que se dirige a ayudarla a decidir para que pueda desarrollar su libertad y su autonomía personal.

PALABRAS CLAVE: Reforma Legislación Civil, apoyos a las personas con discapacidad, ejercicio de la capacidad jurídica de las personas con discapacidad. 


\title{
CONSIDERATIONS ON THE REFORM OF CIVIL LEGISLATION ON DISABILITY: FROM INCAPACITATION TO SUPPORT
}

\begin{abstract}
The reform of civil legislation to support people with disabilities in the exercise of their legal capacity (Law 8/2021, of June 2), seeks to adapt to the New York Convention of 2006 in order to facilitate the taking of own decisions of these people through a model of supports. It does not consist in that the third party that supports replaces the person with intellectual disability, but rather that he makes the necessary support available to him so that he can make his own decisions, getting back his role in making decisions that affect him, becoming active protagonist in the development of his vital project. The intervention of the third party that supports does not have the purpose to replace the person with intellectual disability in decision-making, but is aimed at helping them to decide so that they can develop their freedom and personal autonomy.
\end{abstract}

KEYWORDS: Civil Legislation Reform, support for people with disabilities, exercise of the legal capacity of persons with disabilities.

\section{Consideraciones jurídicas generales en torno a la persona y a la capacidad de la persona}

La persona ocupa un puesto central en todo Ordenamiento Jurídico. Sin la persona, no es imaginable ninguna institución jurídica. En este sentido, F. de CASTRO siempre analizó y desarrolló la concepción del Derecho civil como ordenación de la persona y sus fines en la comunidad².

La significación jurídica de la persona brota de la dignidad como ser racional, libre y conviviente. La autonomía privada, brota y se fundamenta en la persona y su dignidad ${ }^{2}$. La persona, con su dignidad, es la protagonista de las relaciones jurídicas y del derecho subjetivo en sus variadas formulaciones, siendo por ello, el centro y eje del Ordenamiento Jurídico y fundamento único de la autonomía privada, entendida ésta como cualidad de la persona de ser dueño de sí mismo (sui iuris) ${ }^{3}$.

\footnotetext{
${ }^{1}$ DE CASTRO, F., Derecho Civil de España, I, IEP, Madrid, 1955, pp. 126 y ss. Del mismo autor, Derecho Civil de España II, IEP, Madrid, 1964, pp. 170 y ss. HERNÁNDEZ-GIL, A., El concepto de Derecho Civil, Revista de Derecho Privado, Madrid 1943, p. 77, recalcó que el Derecho Civil es el Ordenamiento Jurídico de la persona en sus coordenadas más íntimas y esenciales, siendo la autonomía privada un poder de la esfera jurídica privada que se fundamenta en la persona y su dignidad. Para VALLET DE GOYTISOLO, J.B., Panorama del Derecho Civil, Bosch, Barcelona, 1963, p. 96, la persona -es un prius, una realidad que el Derecho no crea, sino que reconoce y valora jurídicamente-, en cuanto realidad inteligente, libre y portadora de una dignidad absoluta, es titular "perse" de derechos y obligaciones.

${ }^{2}$ ALONSO PÉREZ, M., Consideraciones en torno a la persona y su valoración jurídica. Estudios en Homenaje al Prof. José Ma. Miquel, Vol. I (Coord. Luis Díez-Picazo) Thomson Reuters-Aranzadi, Navarra, p.250, nos recuerda como de la dignidad, Francisco de Vitoria, en sus "Relecciones teológicas", señala que el individuo tiene unos derechos inalienables que constituyen la dignidad humana-, y, también ALONSO PÉREZ nos recuerda que los filósofos escolásticos clásicos -Santo Tomás o los neoescolásticos del S. XVI-, han dicho que la dignidad era la base de la libertad humana... Pufendorf y Kant, siguiendo sus pasos, son los grandes maestros de la dignidad humana como esencia constituyente del ser humano.

${ }^{3}$ Señala "la necesidad de detenernos, aunque sea brevemente, en la significación auténtica de la persona como fuente y razón de ser de la autonomía privada" ALONSO PÉREZ, M., Consideraciones en torno a la persona y su valoración jurídica. Estudios en Homenaje al Prof. José Mª Miquel, Vol. I (Coord. Luis Díez-Picazo) Thomson Reuters-Aranzadi, Navarra, pp. 241 a 268, en concreto la cita es de la página 241. En la página 243 afirma "El Derecho civil contempla a la persona en sus dimensiones más íntimas y generales (como individuo,
} 
Siguiendo estos razonamientos, el artículo 10. 1, de la vigente Constitución Española ${ }^{4}$, se refiere a la dignidad de la persona y a los derechos inviolables que le son inherentes, es decir, esenciales y connaturales a tal dignidad. Nuestro Tribunal Constitucional a la hora de examinar el precepto entiende la "dignidad humana" como el derecho de toda persona a un trato que no contradiga su condición de ser racional, igual y libre, capaz de determinar su conducta en relación consigo mismo y su entorno ${ }^{5}$.

Ahora bien, la dignidad humana, como esencia determinante de la persona, se proyecta socialmente, y sólo si se relaciona con los demás es posible en plenitud. No olvidemos que la persona es un ser hecho para vivir en sociedad, por lo que necesariamente ha de estar presente el Derecho ${ }^{6}$ como elemento esencial para hacer posible la convivencia social.

Según DÍEZ-PICAZO y GULLÓN la persona y la vida social son la razón del Derecho, un prius respecto a éste, puesto que, sin aquellas, éste no existiría "al no poder cumplir su función de instrumento para la organización justa de la convivencia"’.

La dignidad de la persona descansa en su esencia misma de ser humano ${ }^{8}$. La igual dignidad de las personas es generadora de la igualdad en su capacidad jurídica y en su ejercicio. Como sabemos,

como miembro de una familia, en sus relaciones de tráfico y disfrute de bienes, y en su prolongación más allá de la muerte mediante la herencia). También vide ALONSO PÉREZ, M., Reflexiones sobre el concepto y valor de la persona en el "Derecho civil de España", Anuario de Derecho Civil, Vol. 36, Fasc. No 4, 1983, pp. 1117 1128. Concretamente en las pp. 1118 y 1119 escribe "La sustantividad y excelsitud de la persona, que De Castro extrae de la mejor tradición católica nacional, sea de nuestros textos jurídicos-Partidas, Leyes de Toro, etc.sea en especial, de los grandes maestros de la teología -Vitoria, Molina, Suárez, etc.- o del Derecho -A. Agustín, G. López, Covarrubias, etc.- está patente en todo el volumen primero de su magna obra." KANT, E., Metaphisik der Sitten, Ed. Vorländer, Hamburgo, 1922, pp. 343 y ss. considera que la autonomía, o cualidad de la persona de ser dueño de sí mismo (sui iuris), es el fundamento de la dignidad del hombre. También vide ALONSO PÉREZ, M., Reflexiones sobre el concepto y valor de la persona en el "Derecho civil de España", Anuario de Derecho Civil, V.36, no.4, 1983, pp. 1117 a 1128.

${ }^{4}$ Sobre el tema de la persona como titular de Derechos fundamentales vide TORRES GARCÍA, T. F., La persona y el Derecho civil, "Estudios de Derecho civil en homenaje al Prof. José González García, Aranzadi, Navarra, 2013, pp. 163 a 173. GUTIÉRREZ GUTIÉRREZ, I., Dignidad de la persona y derechos fundamentales, Marcial Pons, Madrid, 2005.

${ }^{5}$ STC 192/2003, sobre ella GUTIERREZ GUTIÉRREZ, I., La dignidad quebrada. "Teoría y realidad constitucional", $\mathrm{n}^{\circ} 14,2^{\circ}$ semestre de 2004, pp. 331 a 343, quien pone de manifiesto la idea de hallar en Kant las raíces filosóficas de la dignidad humana y vincular al hombre con los principios de un gobierno adecuado a su dignidad: la libertad, la igualdad y la autodeterminación, y cita a KANT, E., Introducción a la Teoría del Derecho (Introducción a la Metafísica de las Costumbres y a la Teoría del Derecho), Trad. e introducción de F. González Vicen, IEP, Madrid, 1954.

${ }^{6}$ ENGISCH, K., Introducción al pensamiento jurídico, Trad. esp. y adaptación al Código Civil español, Madrid, 1967, pp. 16 y ss. pone de manifiesto que no existe ninguna persona que no viva bajo el Derecho..., y que no esté afectada y guiada por él.

${ }^{7}$ DÍEZ-PICAZO y GULLÓN, A., Sistema de Derecho Civil, Vol. I, 6ª Ed. Tecnos, Madrid, 1988, p. 229.

8 DÍEZ-PICAZO, L., Nota preliminar a su libro "La doctrina del enriquecimiento injustificado", Civitas, Madrid, 1987, se trata del discurso leído el día 14 de diciembre de 1987, en el acto de su recepción como académico de número de la RAJL, y en concreto en su p. 13, señala que "hay un principio básico y cardinal en todo el Derecho civil que es la dignidad de la persona... La persona, decía DE CASTRO, no puede ser una pura exigencia de carácter abstracto o formal de las normas jurídicas o de los derechos subjetivos. No es un capítulo de la teoría de la relación jurídica, del derecho subjetivo o del negocio jurídico, sino el objeto de la primera parte institucional del sistema de Derecho Civil, porque todo él se mueve y gira alrededor de la persona...". PÉREZ BUENO, L.C. y ÁLVAREZ RAMIREZ, G., Los principios, en "Fundamentos del Derecho de la Discapacidad, (Directores De Lorenzo García, L y Pérez Bueno, L.C.), Aranzadi, Navarra, 2020, pp. 139 a 178, en concreto en la p. 143, toma como "fundamento los Derechos Humanos que dotan a la 
en el Ordenamiento Jurídico español, la dignidad de la persona está constitucionalizada ${ }^{9}$, como atributo inseparable de la persona, que como valor opera como criterio hermenéutico en la aplicación normativa.

Todo ser humano es persona y tiene personalidad, cualidad que es una exigencia de la dignidad humana que el Derecho reconoce: ser persona equivale a tener aptitud para ser sujeto de derechos y obligaciones (de relaciones jurídicas). El Código Civil, consciente de ello, dedica su libro Primero a tratar "De las personas", reconociendo el puesto central de la persona en el Ordenamiento Jurídico ${ }^{10}$.

Hasta la entrada en vigor, el día 3 de septiembre del año 2021, de la Ley 8/2021, de 2 de junio, por la que se reforma la legislación civil y procesal para el apoyo a las personas con discapacidad en el ejercicio de su capacidad jurídica, Ordenamiento Jurídico reconoce capacidad a la persona, que puede ser la personalidad o capacidad jurídica, o bien la capacidad de obrar ${ }^{11}$. La primera "es la aptitud o idoneidad para ser titular de derechos y obligaciones. Toda persona, por el mero hecho de serlo, posee capacidad jurídica. La capacidad jurídica, en tal sentido, es atributo o cualidad esencial de ella, reflejo de su dignidad. La capacidad de obrar, en cambio, es la aptitud o idoneidad para realizar eficazmente actos jurídicos, o, en otros términos, la capacidad para adquirir o ejercitar derechos y asumir obligaciones, que puede ser plena o encontrarse limitada si el sujeto no puede realizar por si mismo con plena eficacia actos o negocios jurídicos o algún tipo de ellos (por ejemplo, los de enajenación o gravamen)"12.

Por tanto, todo ser humano, por el mero hecho de serlo tiene personalidad, tiene capacidad jurídica (facultad de titularidad), aptitud para ser sujeto de derechos y obligaciones. No cabe limitarla, ni suprimirla sino por causa de muerte. La aptitud en concreto para realizar actos jurídicos validos asumiendo derechos y obligaciones específicas constituye la capacidad de obrar (facultad de ejercicio). El principio general en nuestro Derecho es el de presunción de capacidad de toda persona y la excepción es la modificación de la capacidad de las personas mediante una sentencia que determina así su estado civil.

Por consiguiente, mientras la capacidad jurídica no admite grados, la capacidad de obrar si, ya que los menores de edad tienen menos capacidad de obrar que los mayores de edad y las personas con la capacidad modificada, tienen personalizado el grado de capacidad de obrar que determina la sentencia judicial que ha graduado su extensión al modificar la capacidad de obrar, ya que ésta no afecta tanto a la titularidad de los derechos de la persona cuanto a la forma de su ejercicio lo que

\footnotetext{
dignidad de un nuevo contenido amplio e infinito del ser humano que incluye a todos los individuos sin tener en cuenta sus rasgos característicos"

9 Art. 10 de la Constitución Española de 1978, establece que: "La dignidad de la persona, los derechos inviolables que le son inherentes, el libre desarrollo de la personalidad, el respeto a la ley y a los derechos de los demás son fundamento del orden político y de la paz social”.

10 Nuestra Constitución y las leyes que la desarrollan consagran el valor central que tiene la persona, sus derechos y libertades fundamentales.

11 FERNÁNDEZ DE BUJAN, A., Capacidad, discapacidad. Incapacitación: Modificación judicial de la capacidad., Revista Jurídica de la Universidad Autónoma de Madrid, n 23, 2011-I, pp. 53 a 81, concretamente en la p. 54 escribe "Los conceptos de capacidad jurídica y capacidad de obrar, pertenecen a la dogmática jurídica moderna que, formulada, en buena medida, por la pandectística alemana del XIX, tiene su fundamento esencial en las fuentes romanas y en la tradición romanística."

${ }^{12}$ DÍEZ-PICAZO y GULLÓN, A., Sistema de Derecho Civil, Vol. I, 6ª Ed., Tecnos, Madrid, 1988, p. 230.
} 
obliga a que en la propia Sentencia de modificación de la capacidad se especifique la situación en que queda la persona conforme a sus conveniencias y necesidades. ${ }^{13}$

Mientras la capacidad jurídica se adquiere por el mero hecho de ser persona y no conoce de graduaciones ni de modificaciones al no verse afectada por las circunstancias personales; la capacidad de obrar puede ser limitada en virtud de determinantes que impiden a las personas gobernarse por si mismas de manera consciente y responsable. Esto hace que la capacidad de obrar no sea la misma para todas las personas ya que algunas tienen limitaciones para tomar decisiones y ejercer su autonomía personal, siendo sustituido por un cargo tuitivo que, a partir del momento de la designación, tomara buena parte de las decisiones personales, y también las patrimoniales ${ }^{14}$, del modo que considere más adecuado para la persona que se le ha modificado su capacidad, sin necesidad de consultarla o de tener presente sus opiniones. La finalidad de este mecanismo de sustitución -tutelaestá en proteger a la persona cuya capacidad ha sido modificada.

En este contexto conceptual ${ }^{15}$, el sistema establecido de las funciones tutelares con arreglo al art. 215 y ss. CC, está basado, en la mayoría de los casos, en la sustitución para la adopción de decisiones por la persona que tiene modificada su capacidad de obrar y queda sujeta al régimen de la tutela ${ }^{16}$. Sin embargo, este sistema tutelar quedará derogado por la Ley 8/2021, de 2 de junio, por la

\footnotetext{
13 "Sabemos que la capacidad jurídica es la aptitud que posee toda persona para ser sujeto de derechos y deberes mientras que la capacidad de obrar es la aptitud de la persona para obrar eficazmente en el ámbito jurídico. La capacidad jurídica no es más que expresión de la igualdad y dignidad de la persona que resalta la Constitución Española. Es por tanto la misma durante toda la vida, uniforme, inmune a graduaciones o modificaciones. Es la que hace al hombre sujeto de Derecho, reflejo de su personalidad y a ella necesaria e inmediatamente conectada. En nada se ve afectada por las circunstancias personales del individuo. La capacidad jurídica no se concede, es una necesidad derivada de la misma personalidad humana...Si la capacidad jurídica es el reflejo directo de la personalidad, la capacidad de obrar la presupone, pero exige un mínimo de madurez en el sujeto para cuidar de su persona y bienes... De ahí que la capacidad de obrar frente a la capacidad jurídica admite graduaciones, porque no son iguales las condiciones de madurez en todas las personas, o si se quiere, su capacidad de entender y querer", GULLÓN BALLESTEROS, A., Capacidad jurídica y capacidad de obrar, en "Los discapacitados y su protección jurídica". Edición Consejo General del Poder Judicial, Madrid, 1999, pp. 13 y 14.

14 Sobre este aspecto GORDILLO CAÑAS, A., Capacidad, incapacidades y estabilidad de los contratos, Tecnos, Madrid, 1986, concretamente en las pp. 199 y ss. se ocupa de la sanción jurídica de la actuación del incapaz, y en particular en las pp. 246 y ss. del ámbito de actuación ineficaz, haciendo casi leit motiv a la estabilidad de los contratos.

${ }^{15}$ Cfr. artículos 199 y 200 del CC, así como los artículos 756 y ss. de la LEC.

${ }^{16}$ Según el art. 757 de la Ley de Enjuiciamiento Civil de 2000, cualquier persona está facultada para poner en conocimiento del Ministerio Fiscal los hechos que pueden ser determinantes de la incapacitación; las autoridades y funcionarios públicos que, por razón de su cargo, conocieran la existencia de posible causa de incapacitación en una persona, están obligados a ponerla en conocimiento del Ministerio Fiscal. DOMÍNGUEZ LUELMO, A. y TORRES GARCÍA, T., La incapacitación, en “Tratado de Derecho de la persona física”, (Gete-Alonso y Calera, M.), Vol. II, Aranzadi, Navarra, 2013, pp. 53 a 121. TORRES GARCÍA, T., Efectos de la incapacitación, en "Tratado de Derecho de la persona física”, (Gete-Alonso y Calera, M.), Vol. II, Aranzadi, Navarra, 2013, pp. 123 a 171. BERROCAL LANZAROT, A.I., La curatela como institución de protección en el marco de la convención sobre los derechos de las personas con discapacidad, en "Análisis crítico de la Jurisprudencia”, Revista Critica de Derecho Inmobiliario, no 732, pp. 2253 a 2478, en concreto en las pp. 2250 y 2251, escribe "Se pretendía el reconocimiento de la unidad de guarda, de ahí que nuestro Código Civil, inspirado en el Code civil, refunde las instituciones tutelares bajo una sola -la tutela-, aunque subsiste una gran variedad de situaciones que determinan que tal situación es más formal que real,...se preveía como único régimen de guarda un sistema de tutela severa que se aplicaba tanto a los locos profundos como a quienes sufrían solamente debilidad o cierto retraso mental...La falta de adecuación de este modelo de protección a las necesidades de la realidad social se puso de manifiesto por nuestro Tribunal Supremo ya a mediados del siglo
} 
que se reforma la legislación civil y procesal para el apoyo a las personas con discapacidad en el ejercicio de su capacidad jurídica ${ }^{17}$, consecuencia de la ratificación por España de la Convención Internacional sobre los Derechos de las Personas con Discapacidad de 2006 ${ }^{18}$. La Convención va

XX...En todo caso, se confirma la tutela como la única institución de guarda legal, pero compuesta por una pluralidad de órganos contenido en el artículo 201...Ante este panorama, y la demanda insistente de la doctrina a favor del restablecimiento de la curatela, la Ley 13/1983, de 24 de octubre de reforma de la tutela modificó la redacción originaria del Código Civil en relación con tal materia fijando como principios fundamentales:1.- La no enumeración taxativa de las causas de incapacitación, sino que genéricamente se identifican con "las enfermedades o deficiencias persistentes de carácter físico o psíquico, que impidan a la persona gobernarse por sí misma" (Art. 200); 2.-Se abandona el sistema de tutela de familia (tutor, protutor y Consejo de Familia), y se sustituye por un sistema de tutela judicial o de autoridad, en la que los órganos tuitivos se adscriben a la autoridad o control del Juez; 3.-Se permite incapacitar a los menores de edad, cuando se prevea razonablemente que la causa de incapacitación persistirá después de la mayoría de edad (art. 201); y, en tal caso, superada la mayoría por el incapacitado, se origina la patria potestad prorrogada, y cuando ella resulte imposible la tutela (art. 171); 4. Además de la tutela y del defensor judicial, se introduce un nuevo órgano tuitivo de la persona, la curatela...supuso su restauración o restablecimiento ante la actitud del legislador de 1889 de ignorarla. Así se da una nueva redacción a los artículos 286 a 293 del Código Civil, estableciendo como criterio determinante de la curatela el grado de discernimiento de la persona sometida al cargo de guarda, con la función clara de asistencia o complemento de capacidad y no de representación. La curatela, por tanto, no se instrumenta para suplir la capacidad de obrar del sometido a ella-como ocurre con la tutela-, sino para completarla en aquellos actos en que la ley exija la intervención del curador, o, en su caso, imponga su asistencia la sentencia de incapacitación o la resolución judicial que la modifique. Esto es, el curador se limita a prestar asistencia en sentido técnico, pero no sustituye la voluntad de la persona sometida a curatela...".

${ }^{17}$ Se refiere a la discapacidad que influye en la capacidad de autogobierno de la persona debido a la alteración intelectual que padece, impidiéndole la formación de una voluntad plenamente consciente y libre -pues la física o sensorial no afecta a dicha capacidad-, es decir a la discapacidad intelectual o psíquica producida tanto por factores genéticos, por lesiones prenatales, por problemas en el parto, por enfermedades infantiles, accidentes de tráfico o por diversos trastornos mentales como la depresión mayor, esquizofrenia o trastorno bipolar, entre otras. Hay que tener presente que, como indica MARTÍNEZ DE AGUIRRE ALDAZ, C., El tratamiento jurídico de la discapacidad psíquica: reflexiones para una reforma legal, Aranzadi, Navarra, 2014, pp. 36-37, las discapacidades psíquicas son muy diferentes entre sí por su origen (nacimiento, sobrevenidas), por su evolución (reversibles o irreversibles, mejorables o no mejorables, progresivas o regresivas...) y sobre todo por el nivel de intensidad en la afección a la capacidad de conocer y querer. Para DÍAZ ALABART, S., Actuación de las personas con discapacidad en el ámbito personal y familiar: el derecho a su libertad personal, en "La voluntad de la persona protegida. Oportunidades riesgos y salvaguardias", (Dir. Pereña Vicente, M.) Dykinson, Madrid, 2019, pp. 163 a 197, en concreto en la p. 167, entiende que homogeneizar el tratamiento jurídico de una y otras discapacidades puede provocar distorsiones, y sobre todo falta de adecuación de ese tratamiento a las peculiaridades de algún tipo concreto de discapacidad".

${ }^{18}$ Instrumento de Ratificación de la Convención sobre los derechos de las personas con discapacidad, hecho en Nueva York el 13 de diciembre de 2006. "BOE" núm. 96, de 21 de abril de 2008, que forma parte del Ordenamiento jurídico español mediante instrumento de ratificación de 23 de noviembre de 2007, desde su publicación en el BOE, a partir del 3 de mayo de 2008. Esta Convención adoptada por la Asamblea General de la ONU (Nueva York), el 13 de diciembre de 2006, forma parte de nuestro Ordenamiento Jurídico, según el art. 96.1 de la Constitución Española y el art. 1.5 del Código Civil. Las Convenciones y Tratado internacionales, una vez ratificados y publicados oficialmente en España, forman parte de nuestro Ordenamiento Jurídico, y las normas jurídicas en ellos contenidas son de aplicación directa, ocupando un valor jerárquico superior a la Ley teniendo presente que los susodichos Tratados internacionales no se puede derogar por ésta, sino que su denuncia debe revestir el mismo procedimiento previsto para su aprobación, art. 96.1 CE. Por otra parte, se ha de tener presente que la Ley Orgánica 1/2008, de 30 de julio, a la vez que autorizó la ratificación del Tratado de Lisboa de 13 de diciembre de 2007 (ratificado por España mediante Instrumento de 26 de septiembre de 2008 -publicado dicho Instrumento de Ratificación en el BOE de 27-11-2009, y en vigor desde el 1 de diciembre de 2009), estableció en su artículo 2 que (a tenor de los dispuesto en el párrafo segundo del art. 10 de la Constitución Española y en el apartado 8 del artículo 1 del citado Tratado de Lisboa) las normas relativas a los Derechos Fundamentales y a las Libertadas que la Constitución reconoce se interpretarán también 
acompañada de un Protocolo de carácter facultativo de la misma fecha, complementario, pero independiente de aquella, mediante el cual todo Estado Parte en el protocolo reconoce las competencias del Comité de Naciones Unidas sobre los Derechos de las Personas con Discapacidad para controlar el correcto cumplimiento de lo establecido en la Convención ${ }^{19}$.

\section{La convención sobre los derechos de las personas con discapacidad, de 13 de diciembre de 2006}

La Convención después de señalar en su art.1.1.su propósito ${ }^{20}$, y de indicarnos qué personas se consideran incluidas entre las personas con discapacidad ${ }^{21}$, señala entre los principios generales que revisten importancia "el respeto de la dignidad inherente, la autonomía individual, incluida la libertad de tomar las propias decisiones, y la independencia de las personas”. En el art. 3 de la Convención de 2006 se recogen los principios de la misma, destacando en la letra del citado precepto, la autonomía individual, incluida la libertad de tomar las propias decisiones, y la independencia de las

de conformidad con lo dispuesto en la Carta de los Derechos Fundamentales publicada en el Diario Oficial de la Unión Europea de 14 de diciembre de 2007, en cuyo artículo 26 se dice que "la Unión reconoce y respeta el derecho de las personas discapacitadas a beneficiarse de medidas que garanticen su autonomía, su integración social y profesional y su participación en la vida de la comunidad." Sobre la discapacidad y su regulación jurídico-privada GARCÍA CANTERO, G., Reflexiones sobre la mejor regulación jurídico-privada de la discapacidad, Revista Jurídica del Notariado, abril-junio de 2012, pp. 207 y ss. También en "Los mecanismos de guarda legal de las personas con discapacidad tras la Convención de las Naciones Unidas" (Coord. Salas Murillo, S.), Dykinson, Madrid, 2013, pp. 41 a 56.

${ }^{19}$ El Reino de España ratificó ambos instrumentos internacionales -la Convención y el Protocolo Facultativosin formular ninguna reserva, mediante Instrumentos de Ratificación de 23 de noviembre de 2007 y publicados en los Boletines Oficiales del Estado de 21 y 22 de abril de 2008, respectivamente, entrando en vigor el día 3 de mayo de 2008. CAMPOY CERVERA, I., La recepción y aplicación en España de la Convención de Naciones Unidas sobre los Derechos de las Personas con discapacidad, Ediciones Laborum, Murcia, 2017. CUENCA GÓMEZ, P. Grandes cuestiones pendientes en el ordenamiento español para acompasarse a los mandatos de la Convención. Libertad personal. En "La convención internacional sobres los Derechos de las personas con discapacidad. De los hechos a los derechos”, (Alcaín Martínez y Álvarez Ramirez), Tirant lo Blanch, Valencia, pp. pp. 132 a 142.

${ }^{20} \mathrm{El}$ propósito de la Convención es promover, proteger y asegurar el goce pleno y en condiciones de igualdad de todos los derechos humanos y libertades fundamentales por todas las personas con discapacidad, y promover el respeto de su dignidad inherente -Art. 1, párrafo $1^{\circ}$. de la Convención-.

${ }^{21} \mathrm{El}$ artículo 3.a) de la Convención señala como en el ámbito de las personas con discapacidad se incluyen a aquellas que tengan deficiencias físicas, mentales, intelectuales o sensoriales a largo plazo que, al interactuar con diversas barreras, puedan impedir su participación plena y efectiva en la sociedad, en igualdad de condiciones con las demás. SÁNCHEZ DE LA TORRE, A. Discapacidad, condición humana y dignidad humana, en "Fundamentos de conocimiento jurídico: La capacidad jurídica, Dykinson, Madrid, 2005, pp. 376 y 387, al tratar la discapacidad afirma "La discapacidad, es una forma de capacidad en que manifiesta una existencia. No es una negación total de capacidad pues ello sería una incapacidad, sino un modo o manera de estar modulada para cada uno el alcance de la propia capacidad, y denota una manera especial de ser capaz". Sobre la evolución en la clasificación de los distintos tipos de discapacidad así como en el tratamiento y la ayuda requerida por las personas que se encuentran en estas situaciones, MARTÍNEZ DIE, R., La protección jurídica de discapacitados, incapaces y personas en situaciones especiales, Civitas, Madrid, 2000; VARGAS CABRERA, B., Aspectos civiles y procesales de la discapacidad, en "La protección jurídica del discapacitado", (Coord. Ignacio Serrano García), Tirant lo Blanch, Valencia, 2003, pp. 121 a 132. PEREÑA VICENTE, M., El incapacitado ante la nueva protección jurídica del discapacitado, Actualidad Civil, no 15, 2004, pp. 1758 a 1772. SERRANO GARCÍA, I., Discapacidad e incapacidad en la Ley 41/2003 de 18 de noviembre, Revista Jurídica del Notariado, 52, octubre-diciembre de 2004, pp. 231 a 274.

REDUR 19 / 2021 
personas, para lo cual la persona con discapacidad ejercitará su capacidad jurídica y si necesita apoyo para tal ejercicio se han de respetar los derechos, la voluntad y las preferencias de esas personas ${ }^{22}$.

La Convención de 2006 supone un cambio de enfoque jurídico de la discapacidad: a la persona discapacitada, no se la debe marginar o excluir, se le debe proporcionar unos apoyos para el ejercicio de su capacidad jurídica ${ }^{23}$. Apoyo para conocer y respetar la voluntad, deseos y preferencia de la persona con discapacidad ${ }^{24}$ a la hora de ejercer su capacidad jurídica ${ }^{25}$. Por tanto, el apoyo no se ha "de ejercitar de un modo objetivo - en interés de las personas con discapacidad-, sino de un modo subjetivo -"atendiendo a la voluntad, deseos y preferencias de las personas" discapacitadas²6.

${ }^{22}$ Se trata de un sistema que otorga protagonismo a la persona en el diseño y gestión de las medidas de apoyo precisas como ponen de manifiesto, entre otros, AMUNÁTEGUI RODRÍGUEZ, A., El protagonismo de la persona con discapacidad en el diseño y gestión del sistema de apoyo, en "Claves para la adaptación del Ordenamiento jurídico privado a la Convención de Naciones Unidas en materia de discapacidad", (Dir. DE SALAS MURILLO, S. MAYOR DEL Hoyo, M.V.), Tirant lo Blanch, Valencia, 2019, pp. 125 a 163; LEGERÉN MOLINA, A., La relevancia de la voluntad de la persona con discapacidad en la gestión de apoyos, en " "Claves para la adaptación del Ordenamiento jurídico privado a la Convención de Naciones Unidas en materia de discapacidad", (Dir. DE SALAS MURILLO, S. MAYOR DEL Hoyo, M.V.), Tirant lo Blanch, Valencia, 2019, pp.165 a 211.

${ }^{23}$ La Sentencia del TS 282/2009, de 29 de abril de 2009, (RJ 2009, 2901), señala ya esta nueva perspectiva jurídica al establecer que: "al enfermo psíquico se le debe proporcionar un sistema de protección, no de exclusión." En la doctrina VIVAS TESÓN, I., Más allá de la capacidad de entender y querer: algunas consideraciones de lege ferenda acerca de la protección de las personas diversamente capaces", en "Estudios de Derecho civil en homenaje al Prof. Joaquín Rams Albesa, (Coord. Cuena Casas, M., Anguita Villanueva, L. y Ortega Domenech, J.) Dykinson, Madrid, 2013, pp. 1655 a 1673; de la misma autora, El ejercicio de los derechos de personalidad de la persona con discapacidad, en "Claves para la adaptación del ordenamiento jurídico privado a la Convención de Naciones Unidas en materia de discapacidad", (Dir. DE SALAS MURILLO, S. y MAYOR DEL HOYO, M.V.), Tirant Lo Blanch, Valencia, 2019, pp. 409 a 443.

${ }^{24}$ PEREÑA VICENTE, M., Derechos fundamentales y capacidad jurídica. Claves para una propuesta de reforma legislativa, Revista de Derecho Privado, núm. 4, julio-agosto, 2016, pp. 3-40, en concreto en la p. 7 , señala que la capacidad se tiene por el hecho de ser persona y no se restringe ni se modifica. PAU PEDRÓN, A. El principio de igualdad y el principio de cuidado, con especial atención a la discapacidad, Revista de Derecho civil, vol. VII, núm. 1, enero-marzo, 2020, Estudios, pp. 3-29, en especial, en la p. 5 alude a que "la prestación de cuidado no supone un menoscabo de la autonomía, porque el cuidado no supone autoritarismo, ni dominación, ni paternalismo, sino por el contrario un reforzamiento de su autonomía, ya que el cuidado no debe ejercerse "con la mejor intención"... del cuidador, sino conforme a la voluntad de la persona cuidada, de manera que el cuidado no supone heteronomía, sino un reforzamiento de la autonomía..."

${ }^{25} \mathrm{El}$ apoyo, medida dinámica, orientada a acompañar, informar, orientar, aconsejar, ayudar en la comprensión y razonamiento de los aspectos necesarios en la toma de decisiones, en la práctica puede comportar problemas vg. si el que presta el apoyo asume una obligación de medios o de resultado, hasta donde llega su diligencia exigible, el posible desacuerdo entre el prestador de apoyos y la persona que ha de recibirlos, o la oposición a recibir el apoyo de la persona que ha de recibirlos en aras de su autonomía de la voluntad ... como pone de manifiesto DE SALAS MURILLO, S., Significado jurídico del "apoyo en el ejercicio de la capacidad jurídica" de las personas con discapacidad: presente tras diez años de Convención. Revista doctrinal Aranzadi civilmercantil, $\mathrm{n}^{\circ}$ 5, 2018, pp. 1-33, en concreto las pp. 10, 11, 22 y 25. Sobre el particular vide también ECHEVARRÍA DE RADA, T. Autonomía de la voluntad y exigencia de forma en determinados instrumentos de protección de personas especialmente vulnerables, Aranzadi civil-mercantil, Revista doctrinal, Vol. 2, n ${ }^{\circ} 7$, noviembre, 2013, pp. 67 a 109. ROVIRA SUEIRO, Ma . E., La convención de las Naciones Unidas sobre los derechos de las personas con discapacidad: su impacto en el ordenamiento jurídico español, en "Instrumentos de Protección de la discapacidad a la luz de la Convención de Naciones Unidas", Aranzadi, Navarra, 2016, pp. 15 a 61; LEGERÉN MOLINA, A., y ROVIRA SUEIRO, M.E., Instrumentos de protección de la discapacidad a la luz de la Convención de Naciones Unidas, Cizur Menor, Thomson-Reuters. Aranzadi, 2015.

${ }^{26}$ PAU PEDRÓN, A., De la incapacitación al apoyo: el nuevo régimen de la discapacidad intelectual en el Código Civil, Revista de Derecho Civil, Vol. V, núm. 3, julio-septiembre de 2018, pp. 5 a 28, concretamente 


\section{II.1. El art. 12 de la convención a la luz de las observaciones del Comité sobre los Derechos de las Personas con Discapacidad}

El artículo 12 de la Convención, incide, de manera profunda, dentro del Derecho privado ${ }^{27}$, particularmente en las instituciones del Derecho de la persona, en lo atinente a la capacidad de las personas con discapacidad y en cuanto el ejercicio de su capacidad de actuar ${ }^{28}$. La capacidad personal es una capacidad jurídica, indivisible, comprensiva tanto de la aptitud para ser titular de derechos como para el ejercicio de los mismos, igual en todos los seres humanos. La Convención excluye la desigualdad en el ejercicio de la capacidad jurídica por la mera discapacidad de la persona, teniendo presente que los Estados Partes adaptaran las medidas pertinentes para proporcionarle a la persona con discapacidad el necesario apoyo para el ejercicio de su capacidad jurídica.

El artículo 12 se rubrica "igual reconocimiento como persona ente la ley" ${ }^{29}$. En su párrafo primero establece que "Los Estados Partes reafirman que las personas con discapacidad tienen derecho en todas partes al reconocimiento de su personalidad jurídica." ${ }^{30}$. Se reafirma, pues, ese derecho -personalidad jurídica- de las personas con discapacidad que existía antes de la

sobre estos aspectos de las personas con discapacidad, pp. 8 y 9. Reflexionan sobre el tratamiento jurídico de la discapacidad intelectual PARRA LUCAN, M. A., La voluntad y el interés de las personas vulnerables. Modelos para la toma de decisión en asuntos personales, Ed. Ramón Areces, Madrid, 2015, y MAYOR DEL HOYO, M.V., El nuevo modelo de protección de las personas con discapacidad. Desamparo, intervención de las Entidades Públicas y acogimiento familiar, Thomson Reuters-Aranzadi, Cizur Menor, 2013.

27 GARCÍA RUBIO, Ma P., Algunas propuestas de reforma del Código Civil como consecuencia del nuevo modelo de discapacidad. En especial en materia de sucesiones, contratos y responsabilidad civil, Revista de Derecho Civil, Vol. V, núm. 3 (julio-septiembre), 2018, pp. 173-197, en concreto en la p.174 señala, refiriéndose a la reforma abordada en la Comisión General de Codificación: "no puede quedar limitada a aquella parte del Código Civil que tradicionalmente contiene las normas relativas a las personas con limitaciones en ejercicio de su capacidad. Muy al contrario, bien puede decirse que ese nuevo modelo constituye un auténtico tsunami que afecta a todo el ordenamiento jurídico, de suerte que prácticamente ninguna norma que implique ejercicio de derechos por parte de sujetos privados va a quedar inmune a la necesidad de adaptación".

28 FERNÁNDEZ DE BUJAN, A., Capacidad, discapacidad, incapacitación: Modificación judicial de la capacidad, Revista Jurídica Universidad Autónoma de Madrid, núm. 23, 2011, pp.53-81, publicado también en RDUNED. Revista de Derecho UNED, no 9, 2011, pp. 83- 92; Revista General de Derecho Romano, $\mathrm{n}^{\circ} 17$, 2011. Del mismo autor, Convención de 2006 sobre los derechos de las personas con discapacidad y proceso de incapacitación, ICADE: Revista de la Facultad de Derecho, no 83-84, 2, 2011, pp. 119-155. También FERNÁNDEZ DE BUJAN, A., Capítulo VII. Incapacitación y discapacidad, en "Derecho de Familia", (Coord. Gema Díez-Picazo Giménez), 2012, pp. 1903 a 1954.

${ }^{29}$ Instrumento de Ratificación de la Convención sobre los derechos de las personas con discapacidad, hecho en Nueva York el 13 de diciembre de 2006. "BOE” núm. 96, de 21 de abril de 2008, Sobre este precepto, vide PÉREZ DE ONTIVEROS BAQUERO, M. ${ }^{a}$ C., La convención internacional sobre los derechos de las personas con discapacidad y el sistema español de modificación de la capacidad de obrar, Derecho Privado y Constitución, núm. 23, 2009, pp. 335 a 368.

30 TORRES COSTAS, Mª E. La capacidad jurídica a la luz del artículo 12 de la Convención de las Naciones Unidas sobre los Derechos de las personas con discapacidad, Agencia Estatal Boletín Oficial del Estado, Madrid, 2020, de la p. 25 a la p. 117 estudia el nacimiento del artículo 12 de la Convención (antecedentes, negociación, entrada en vigor, informes...), de la p. 119 a la p. 221 analiza los avances producidos en la normativa sobre la capacidad jurídica en España, y de p. 223 a la p. 423 desarrolla las cuestiones pendientes en relación con el susodicho art.12 en el anteproyecto de ley por la que se reforma la legislación civil y procesal en materia de apoyo al ejercicio de la capacidad jurídica. 
Convención ${ }^{31}$. Todo ser humano cuenta con personalidad jurídica, lo cual según el Comité sobre los Derechos de las personas con discapacidad 32 "es un requisito indispensable para que se reconozca la capacidad jurídica de la persona"33.

En los apartados segundo y tercero del citado precepto se dice:

"2. Los Estados Partes reconocerán que las personas con discapacidad tienen capacidad jurídica en igualdad de condiciones con las demás en todos los aspectos de la vida”. Según el Comité sobre los Derechos de las personas con discapacidad, la capacidad jurídica incluye la capacidad de ser titular de derechos y la de actuar en derecho, lo cual concede a la persona la protección plena de sus derechos por el Ordenamiento Jurídico. La capacidad jurídica de actuar en derecho reconoce a la persona con discapacidad como actor facultado para realizar transacciones y para crear relaciones jurídicas, modificarlas o ponerles fin. Por consiguiente, a la persona con discapacidad se le reconoce las dos facetas de la capacidad que hasta ahora distinguimos: la capacidad jurídica y la capacidad de obrar. La aptitud para tomar decisiones de la persona con discapacidad impide retirar la capacidad de actuar $^{34}$ y comprender, entender, expresarse en defensa de sus intereses, acudiéndose a las medidas de apoyo si fuese necesario sin modificar su capacidad jurídica: el interesado puede ejercitar su capacidad jurídica por si o con apoyos.

“3. Los Estados Partes adoptarán las medidas pertinentes para proporcionar acceso a las personas con discapacidad al apoyo que puedan necesitar en el ejercicio de su capacidad jurídica." Según el Comité sobre los Derechos de las personas con discapacidad, el apoyo para tomar decisiones que tengan efectos jurídicos, no debe consistir en decidir por ellas, debiendo respetarse, en todo

${ }^{31}$ MAYOR FERNÁNDEZ, D. La reforma de la protección jurídica civil de la discapacidad y la convención de Nueva York de 13 de diciembre de 2006, Boletín del Ministerio de Justicia, Año LXV, no 2133, julio 2011, pp. 10 a 37, concretamente en la p. 3 entiende que de la incardinación de la Convención de 2006 en el bloque jurídico internacional relativo a los derechos humanos se derivan importantes consecuencias: la primera, sitúa el rengo formal de la Convención dentro del canon interpretativo de nuestros propios derechos constitucionales -art.10.2 CE-; la segunda, su peculiar naturaleza-norma relativa a los derechos humanos- hace que parte de la doctrina reduce su contenido al propio de los principios generales del derecho, cuando en su texto el contenido esencial de sus normas jurídicas es vinculante, aunque en tales declaraciones sobre derechos humanos "empleen un lenguaje descriptivo para desarrollar una función prescriptiva".

32 Creado por el art. 34 de la propia Convención de 2006.

${ }^{33} \mathrm{CRPD} / \mathrm{C} / \mathrm{GC} /$ 1,3 a 8 . Observación general núm.1 (2014), y para su consulta vide https://www.ohchr.org/EN/HRBodies/CRPD/Pages/GC.aspx. Sobre el valor jurídico de estas observaciones como criterios interpretativos, aclaratorios o de interpretación autorizada de la Convención de 2006, vide a CUENCA GÓMEZ, P., El sistema de apoyo en la toma de decisiones desde la Convención Internacional sobre los Derechos de las Personas con Discapacidad: principios generales, aspectos centrales e implementaciones en la legislación española, REDUR, No. 10, diciembre 2012, pp. 61 a 94. También de esta misma autora, La igualdad en la capacidad jurídica de las personas con discapacidad: algunas implicaciones del art. 12 de la CDPD en el Ordenamiento Jurídico Español, Instituto de Derechos Humanos "Bartolomé de las Casas", Madrid, 2010; DE SALAS MURILLO, S., Significado jurídico del “apoyo en el ejercicio de la capacidad jurídica" de las personas con discapacidad: presente tras diez años de Convención. Revista doctrinal Aranzadi civil-mercantil, n 5, 2018, pp. 2 a 6.; MARTÍNEZ DE AGUIRRE ALDAZ, C., Curatela y representación: cinco tesis heterodoxas y un estrambote, en "Claves para la adaptación del ordenamiento jurídico privado a la Convención de Naciones Unidas en materia de discapacidad” (Dir. DE SALAS MURILLO, S., Y MAYOR DEL HOYO, M.V.), Tirant lo. Blanch, Valencia, 2019, pp. 253 a 270, en concreto en la pp. 256 y 257. RECOVER BALBOA, T. Hacia la reforma del Código Civil y la Ley de Enjuiciamiento Civil en materia de discapacidad, en "Nuevas perspectivas del tratamiento jurídico de la discapacidad y la dependencia" (Dir. García Garnica, M.C.), Dykinson, Madrid, 2017, pp. 19 y ss.

${ }^{34}$ CRPD/C/GC/ 1,3 a 8. Observación general núm.1 (2014), y para su consulta vide

https://www.ohchr.org/EN/HRBodies/CRPD/Pages/GC.aspx 
momento, la autonomía individual y la capacidad de las personas con discapacidad para tomar sus decisiones ${ }^{35}$.

En estos dos apartados, segundo y tercero del art. 12, se señalan dos aspectos fundamentales: uno, que las personas con discapacidad tienen capacidad jurídica igual que las demás personas; dos, se diseña el paradigma de los apoyos que puedan necesitar las personas con discapacidad en el ejercicio de su capacidad jurídica ${ }^{36}$.

El párrafo 4 del art. 12 establece las salvaguardias o garantías que deben respetarse en el ejercicio de la capacidad jurídica de las personas con discapacidad que las necesiten: "Los Estados Partes asegurarán que en todas las medidas relativas al ejercicio de la capacidad jurídica se proporcionen salvaguardias adecuadas y efectivas para impedir los abusos de conformidad con el derecho internacional en materia de derechos humanos. Esas salvaguardias asegurarán que las medidas relativas al ejercicio de la capacidad jurídica respeten los derechos, la voluntad y las preferencias de la persona, que no haya conflicto de intereses ni influencia indebida, que sean proporcionales y adaptadas a las circunstancias de la persona, que se apliquen en el plazo más corto posible y que estén sujetas a exámenes periódicos por parte de una autoridad o un órgano judicial competente, independiente e imparcial. Las salvaguardias serán proporcionales al grado en que dichas medidas afecten a los derechos e intereses de las personas".

Según el Comité sobre los Derechos de las personas con discapacidad, el objetivo de tales salvaguardias será el de garantizar el respeto de los derechos, la voluntad y las preferencias de la persona, que incluye el derecho a asumir riesgos y cometer errores. Cuando, pese a haber hecho un esfuerzo considerable, no sea posible determinar la voluntad y las preferencias de una persona con discapacidad, se sustituirá por la "mejor interpretación posible de la voluntad y las preferencias" de esa persona. Además, las salvaguardias deben incluir la protección contra las influencias indebidas, que se producen cuando la calidad de la interacción entre la persona que presta el apoyo y la que lo recibe presenta señales de miedo, agresión, amenaza, engaño o manipulación ${ }^{37}$.

De acuerdo con todo lo anterior, el Comité sobre los Derechos de las personas con discapacidad entiende que se han de suprimir y reemplazar los regímenes basados en la sustitución ${ }^{38}$

${ }^{35} \mathrm{CRPD} / \mathrm{C} / \mathrm{GC} / 1,3$ a 8. Observación general núm.1 (2014), y para su consulta vide https://www.ohchr.org/EN/HRBodies/CRPD/Pages/GC.aspx

${ }^{36}$ En el art. 12, apartados 2 y 3, se diseña "el paradigma de los apoyos que puedan necesitar las personas con discapacidad en el ejercicio de su capacidad jurídica, piedra angular de todo el sistema pues éstos pasan a representar el motivo central de cambio legislativo que se avecina: el tradicional modelo de la discapacidad, basado en la sustitución y en la menor capacidad, deberá ser reemplazado por otro cuyo centro neurálgico resida en los apoyos a la capacidad de la persona y a sus potencialidades" GARCÍA PONS, A., El artículo 12 de la Convención de Nueva York de 2006 sobre los Derechos de las Personas con Discapacidad y su impacto en el Derecho Civil de los Estados signatarios: el caso de España, Anuario de Derecho Civil, t. LXVI, 2013, fasc. I, p. 59 a 147, en concreto p. 66.

${ }^{37} \mathrm{CRPD} / \mathrm{C} / \mathrm{GC} / 1,3$ a 8. Observación general núm.1 (2014), y para su consulta vide https://www.ohchr.org/EN/HRBodies/CRPD/Pages/GC.aspx

${ }^{38} \mathrm{El}$ art. 12 de la Convención de 2006 propugna remplazar "los regímenes de sustitución en la adopción de decisiones por una asistencia para la toma de decisiones que respeten la autonomía, la voluntad y las preferencias de la persona", Observaciones finales sobre el Informe presentado por España en virtud del art. 35 de la Convención realizadas por el Comité sobre los Derechos de las personas con discapacidad de 23 de septiembre de 2011. Se trata de no privar del ejercicio de la capacidad jurídica a la persona con discapacidad y de que desaparezcan por completo los regímenes de sustitución en la adopción de decisiones, introduciendo mecanismos de apoyo para la adopción de decisiones que respeten la voluntad y las preferencias de las personas con discapacidad. 
en la adopción de decisiones -vg. el de tutela- por sistemas de apoyo para la adopción de decisiones por las personas con discapacidad que respete su autonomía, su voluntad y sus preferencias ${ }^{39}$.

Por último, el apartado quinto del art. 12, viene a consignar que: "Sin perjuicio de lo dispuesto en el presente artículo, los Estados Partes tomarán todas las medidas que sean pertinentes y efectivas para garantizar el derecho de las personas con discapacidad, en igualdad de condiciones con las demás, a ser propietarias y heredar bienes, controlar sus propios asuntos económicos y tener acceso en igualdad de condiciones a préstamos bancarios, hipotecas y otras modalidades de crédito financiero, y velarán por que las personas con discapacidad no sean privadas de sus bienes de manera arbitraria."

\section{II.2. El art. 12 de la convención de 2006 y la capacidad de la persona con discapacidad}

Como he expuesto, el artículo 12 de la Convención en su apartado segundo, alude a la capacidad jurídica, y en su apartado tercero se refiere al apoyo que puedan necesitar las personas con discapacidad en el ejercicio de su capacidad jurídica, entendido este ejercicio como una acepción amplia que reconoce -y garantiza, en la medida de posible- la capacidad de obrar de las personas con discapacidad. Así, con arreglo a la susodicha interpretación del art 12 de la Convención, el ejercicio de la capacidad jurídica comprende no solo la aptitud para ser titular de derechos y obligaciones sino, también, la idoneidad para ejercitarlos produciendo efectos jurídicos válidos y eficaces.

Un elemento de la dignidad, que se encuentra estrechamente relacionado con el fenómeno de la discapacidad, es la autonomía individual, al que la Convención le concede relevancia ${ }^{40}$, pues ya en su preámbulo se refiere a "la importancia que para las personas con discapacidad reviste su autonomía e independencia individual, incluida la libertad de tomar sus propias decisiones". Por tanto, es, en esencia, la libertad de elección, como componente de la dignidad, el eje a partir del cual la Convención debe ser interpretada y aplicada.

Se reconoce por la Convención de 2006 la libertad de las personas con discapacidad para decidir, por si mismas, en todo lo concerniente al desarrollo de su personalidad y su forma de vida ${ }^{41}$.

Con base al principio general de la dignidad humana, ninguna persona que al nacer adquiere personalidad jurídica puede ver cercenado el ejercicio de su capacidad jurídica -anulada su capacidad de obrar- en el tráfico jurídico en virtud de unas circunstancias personales (deficiencias psíquicas, físicas o sensoriales) ${ }^{42}$, para lo cual los Estados Partes adoptarán las medidas pertinentes para proporcionar acceso a las personas con discapacidad al apoyo que puedan necesitar en el ejercicio de su capacidad jurídica ${ }^{43}$.

${ }^{39} \mathrm{CRPD} / \mathrm{C} / \mathrm{GC} / 1,3$ a 8 . Observación general núm.1 (2014), y para su consulta vide https://www.ohchr.org/EN/HRBodies/CRPD/Pages/GC.aspx

${ }^{40}$ Cfr. Art. 3.a de la Convención de 2006.

41 PÉreZ BUENO, L. C., y ÁlVAreZ RAMireZ, G., Los Principios, en "Fundamentos del Derecho de la Discapacidad”, (Dirs. Lorenzo García, R. y Pérez Bueno, L.C.), Aranzadi, Navarra, 2020, pp. 139 a 178, en concreto pp. 144 y 145.

42 Como señala el preámbulo de la Convención de 2006, uno de los propósitos fundamentales de la misma es la de garantizar que las personas con discapacidad ejerzan plenamente y sin discriminación alguna sus derechos, sobre estos aspectos VERDERA IZQUIERDO, B., La modificación y reintegración de la capacidad de obrar. El principio de no discriminación. En "La encrucijada de la incapacitación y la discapacidad", Coord. Pérez de Vargas Muñoz y Pereña Vicente, Vol. 2, La Ley, Madrid, 2011, pp. 415-428.

43 Art. 12.3 de la Convención de 2006. 
Las circunstancias personales no deberán impedir a las personas con discapacidad el pleno goce de sus derechos, aunque, en casos excepcionales - pensemos en una discapacidad psíquica severa-, pueden entorpecer su ejercicio al incidir gravemente en la capacidad de autogobierno para adoptar decisiones adecuadas relativas a su esfera personal y/o patrimonial ${ }^{44}$.

El espíritu del art.12 de la Convención es el del reconocimiento del ejercicio de la capacidad jurídica universal -que comprende también la capacidad de obrar- para toda persona con discapacidad. Este ámbito técnico jurídico del ejercicio de la capacidad jurídica conduce a que toda persona con discapacidad, además de ser titular de derechos - cuenta con plena aptitud para ejercitar por sí mismo esos derechos-, puede contraer obligaciones que pueden conllevar también, en su caso, el deber de responder por ellas, y por tanto ser sujeto de imputación de responsabilidad ${ }^{45}$.

El nuevo sistema de la Convención de 2006, parte de la idoneidad de la persona con discapacidad intelectual ${ }^{46}$ para el ejercicio de su capacidad jurídica, potencia y apoya la autonomía personal y la toma de decisiones mediante su autonomía individual en los asuntos que le son propios.

El artículo 12 de la Convención de 2006 constituye uno de los aspectos más trascendentales de la misma. No obstante, por su enjundia, está generando ciertas dificultades para su adecuada acomodación en los esquemas tradicionales de nuestro Derecho Civil, planteándose cuestiones como las siguiente: ¿sigue siendo válida la distinción entre la capacidad jurídica y la capacidad de obrar de la persona ${ }^{47}$ ?, ¿se han unificado ambas en el llamado ejercicio de la capacidad jurídica? Varias han sido las posiciones que la doctrina y la jurisprudencia han adoptado al respecto.

\section{II.3. La permanencia de la teoría clásica de la capacidad de la persona}

La distinción entre capacidad jurídica y capacidad de obrar está muy arraigada en nuestro Derecho ${ }^{48}$. Prima facie, se puede interpretar que el artículo 12 de la Convención de 2006, distingue los dos conceptos clásicos -capacidad jurídica y capacidad de obrar- referidos a las personas con discapacidad intelectual -psíquica-, ya que las personas con discapacidad física o sensorial (dejando

44 ARIJA SOUTULLO, C., Algunas consideraciones sobre la reforma legal en materia de modificación judicial de la capacidad y de las medidas de protección a las personas con capacidad modificada, Estudios en Homenaje al Prof. José Ma . Miquel, Vol. I (Coord. Luis Díez-Picazo) Thomson Reuters- Aranzadi, Navarra, pp.387 a 408 , en concreto en la p. 389.

45 Trata sobre estos aspectos, distinguiendo entre "legal capacity" y "capacity of right" BARRIO GALLARDO, A., La repercusión del artículo 12 de la Convención de Nueva York sobre el sistema tutelar español, Estudios en Homenaje al Prof. José Ma . Miquel, Vol. I (Coord. Luis Díez-Picazo) Thomson Reuters- Aranzadi, Navarra, pp. 465 a 485, en concreto en la p.468.

46 MARTÍNEZ DE AGUIRRE, C., El tratamiento jurídico de la discapacidad mental o intelectual tras la Convención sobres los Derechos de las personas con discapacidad, en "Los mecanismos de guarda legal de las personas con discapacidad tras la Convención de Naciones Unidas”, (Coord. SALAS MURILLO, S.), Dykinson, Madrid, 2013, pp. 15 a 40.

${ }^{47}$ En el Derecho español fue DE CASTRO Y BRAVO, F., Derecho civil de España, Tomo II (Derecho de la Persona), Instituto de Estudios Políticos, Madrid, 1952, pp. 20 y ss., quien estableció y definió los conceptos de persona, personalidad, capacidad jurídica y capacidad de obrar."

${ }^{48} \mathrm{La}$ distinción entre capacidad jurídica y de obrar está presente en la doctrina civilista, por todos GETEALONSO Y CALERA, Ma DEL C., Capacidad de obrar y ejercicio de los derechos de la personalidad de la persona con discapacidad, en "Estudios sobre Dependencia y Discapacidad" (Dir. Ma . del Carmen García Garnica), Aranzadi, Navarra, 2011, pp. 41 y ss., en particular pp. 42 a 45. 
aparte las dificultades de movilidad, accesibilidad...), en general, salvo en alguna manifestación severa, no tienen modificada su capacidad de obrar.

La cuestión se plantea en relación con las personas con discapacidad intelectual o psíquica, y fundamentalmente en lo relativo a las personas que tengan manifestaciones más severas. Cuando el art. 12 de la Convención, en sus primeros párrafos se refiere a personalidad jurídica y capacidad jurídica, se está refiriendo a la aptitud de toda persona con discapacidad para ser titular de derechos y obligaciones jurídicas; mientras que cuando en los párrafos tercero y cuarto, se refiere al "ejercicio de la capacidad jurídica" hace referencia a la capacidad de ejercicio efectivo de los derechos-ejercicio con eficacia de éstos en Derecho- y asunción de las obligaciones, se está refiriendo a la capacidad de obrar ${ }^{49}$.

Cuando el artículo 12.2 de la Convención proclama "el principio de igualdad ante la ley de las personas con discapacidad en igualdad de condiciones que las demás", no unifica la capacidad jurídica y de obrar, como algunos afirman ${ }^{50}$, puesto que distingue entre la primera -prevista en el art. 12.2- y la segunda -art.12.3 in fine-"ejercicio de su capacidad jurídica"-.

La Convención alude a la capacidad jurídica y al ejercicio de la capacidad jurídica, lo cual es suficiente para distinguir entre capacidad jurídica y capacidad de obrar, pero, aunque no fuese así, no es motivo para obligar a los Estados Partes a prescindir de tan útil distinción, aunque prevalezca el sistema de apoyo basado en la asistencia -en el que prima la curatela-sobre el de sustitución -en el que se impone la tutela-, que resulta más acorde con la libertad y dignidad de la persona, debiendo acudirse a la sustitución para los casos extremos de ausencia de autogobierno, y prevaleciendo siempre el interés de la persona con discapacidad ${ }^{51}$.

No obstante, dada la vocación universal de la Convención de 2006, ésta utiliza formulaciones lo suficientemente genéricas como para que estén englobados sistemas diferentes de protección: "Es decir, que la Convención no pretende imponer a todos los Estados que sustituyan sus propias instituciones por otras, sino que lo que pretende es que cada Estado respete sus postulados y principios, pero sin imponer determinadas instituciones" ${ }^{\prime 2}$.

En todo caso, dadas las dificultades por las que se atravesó en la redacción del art. 12 de la Convención ${ }^{53}$, lo que queda claro es que este precepto no pretende la distinción entre la capacidad

49 GARCÍA PONS, A., Las personas con discapacidad en el Ordenamiento Jurídico español, Editorial Universitaria Ramón Areces, Madrid, 2008, pp. 45 a 47. SERRANO GARCÍA, I., Autotutela. El artículo 223II del Código Civil y la Convención de Nueva York sobre los derechos de las personas con discapacidad de 2006, Tirant lo Blanch, Valencia, 2012, p. 24.

50 "El principio de igualdad ante la ley de las personas con discapacidad en igualdad de condiciones que las demás unifica la capacidad jurídica y de obrar en un todo inseparable” PÉREZ BUENO, L. C., y ÁLVAREZ RAMIREZ, G., De las personas, en "Fundamentos del Derecho de la Discapacidad", (Dir. Lorenzo García, R. y Pérez Bueno, L.C.), Aranzadi, Navarra, 2020, pp. 255 a 271, en concreto p. 262.

51 RAMS ALBESA, J., Hombre y persona. Personalidad. Capacidad e incapacidad. Discapacidad y vejez (Reflexiones sobre estos conceptos jurídicos esenciales, de ordinario tratados como lugares comunes) Revista Crítica de Derecho Inmobiliario, enero-febrero de 2011, pp. 21 y ss., especialmente las pp. 253, 254 a 256, 283,287 a 290.

52 PEREÑA VICENTE, M., La convención de Naciones Unidas y la nueva visión de la capacidad jurídica, en "La encrucijada de la incapacitación y la discapacidad" (Dir. Pérez de Vargas Muñoz, J. y Coord. Pereña Vicente, M.), La Ley, Las Rozas, Madrid, 2011, pp. 195 y ss. en particular pp. 203 a 205.

${ }^{53}$ La versión en lengua inglesa de este precepto alude a "legal capacity", coincidiendo en español, usualmente, con la expresión capacidad jurídica, y así aparece traducida en el instrumento de ratificación realizado por el Reino de España. Sin embargo, el sentido de esas palabras en relación con el contexto de las negociaciones, los 
jurídica y la capacidad de obrar con fines discriminatorios. Al contrario, pretende asegurar que las personas con discapacidad psíquica -salvo que la deficiencia sea severa-, puedan ejercitar su capacidad jurídica, (su capacidad de obrar), por si mismas o con los apoyos necesarios para lograr la igualdad de oportunidades que deben gozar las personas con discapacidad en las mismas condiciones que los demás (artículos 3, 5 y $12 \ldots$ de la Convención de 2006).

\section{II.4. La unificación de la capacidad de la persona tras la convención de 2006}

Existe una postura doctrinal distinta de la anterior posición clásica acerca de la "capacidad jurídica" a la que se refiere el art.12 de la Convención. Defiende esta postura que el término "capacidad jurídica" ha de ser entendido como "capacidad de actuar en Derecho" que tiene la persona con discapacidad, puesto que su cualidad de ser titular de derechos y obligaciones jurídicas está contemplada en el apartado 1 del art. 12 cuando se refiere a la "personalidad jurídica", que es inherente a la persona y, en general, forma parte de sus derechos humanos inalienables ${ }^{54}$. En definitiva, la personalidad jurídica, es una cuestión de derechos humanos que va implícita en la misma cualidad de ser persona, sin que sea preciso considerarla como un tipo de capacidad de obrar o de ejercicio. Por tanto, desde este planteamiento, la capacidad jurídica a que alude el art. 12.2 abarcará, no sólo comprende la aptitud para ser titular de derechos y obligaciones jurídicas inherentes a toda persona, sino también la de ejercitar tales derechos y obligaciones. En suma, se englobaría en dicho término tanto la capacidad de goce como la de ejercicio ${ }^{55}$.

Ya, antes de la Convención de 2006, Ángel SANCHEZ DE LA TORRE, refiriéndose a la distinción entre capacidad jurídica y de obrar, defendía que "el primero de esos conceptos es simplemente personalidad jurídica, en cuanto aptitud subjetiva de ser mero titular de relaciones jurídicas, y la capacidad jurídica es formal y estrictamente el conjunto de todas las facultades operativas, tanto lícitas como ilícitas, de un sujeto jurídico al que se le imputarán las consecuencias de sus actos jurídicamente relevantes" ${ }^{\prime 6}$.

Desde este planteamiento, se considera que la actual regulación de la capacidad jurídica y de obrar, en particular, en lo referido a la incapacitación, entra en frontal colisión con lo señalado en el art.12 de la Convención "que integra dentro del concepto de capacidad jurídica a la capacidad de

antecedentes legislativos en los trabajos preparatorios, así como atendiendo al espíritu y finalidad de aquéllas, pareciera muy distinto al de su significado técnico jurídico en la tradición continental-romano-francesa, en la que se enmarca nuestro Ordenamiento Jurídico.

${ }^{54} \mathrm{El}$ instrumento por excelencia sobre Derechos Humanos lo constituye la Declaración Universal de Derechos Humanos de 10 de diciembre de 1948, así como los Pactos Internacionales sobre la materia, que son aplicables a toda persona sin distinción.

55 Mientras que LEGEREN MOLINA, A., La tutela del incapaz ejercitada por la entidad pública. Estudios del art. 239.3 del Código Civil, Editorial Universitaria Ramón Areces, Madrid, 2012, p. 28, nota 10, admite que puede replantearse, a la vista de la Convención de 2006, la tradicional distinción entre capacidad jurídica y de obrar, SANTOS URBANEJA, F., Crónica de Presvitonia. A propósito de los efectos en el Código Civil de la Convención de las Naciones unidas sobre Derechos de las Personas con Discapacidad; en "Conclusiones de las Jornadas Fiscales especializadas en la protección de la persona con discapacidad y tutelas”, Madrid, 2009, pp. 25 y 26, LexFamily.es, Revista digital de Derecho de familia, 10 y en (www.fiscal.es), considera que se engloban los conceptos de capacidad jurídica y capacidad de obrar en uno solo, la capacidad jurídica aunque “ello supondría una revolución de tal dimensión que, en este momento, podría conducir a cuotas de inseguridad jurídica muy notables".

56 SÁNCHEZ DE LA TORRE, A., Capacidad, personalidad jurídica, derecho subjetivo, responsabilidad, en "Fundamentos de conocimiento jurídico. La capacidad jurídica”, Dykinson, Madrid, 2005, p. 23. 
obrar entendida como facultad de crear, modificar o extinguir relaciones jurídicas y restringe, e incluso podríamos decir que prohíbe, el instrumento de la incapacitación (en el caso de que éste sea entendido como mecanismo de anulación de la capacidad de obrar, por tanto, ahora también de la capacidad jurídica)" ${ }^{57}$.

Desde este planteamiento se afirma que "la expresión capacidad jurídica empleada por la Convención ha de entenderse también en el sentido de la capacidad de obrar; es decir, tanto la aptitud para ser titular de derechos y obligaciones como la capacidad para realizar eficazmente actos jurídicos. El objetivo de la Convención es afirmar indubitadamente que la persona con discapacidad tiene derechos, es capaz y debe ser capaz de actuar por sí misma. Cuando el ejercicio de la capacidad jurídica necesite apoyos, éstos habrán de ser respetuosos con los derechos, la voluntad y las preferencias de la persona con discapacidad, proporcionados y adaptados a sus circunstancias" 58 .

La discapacidad por sí misma, no es motivo para limitar o restringir la capacidad para ejercer libremente los derechos fundamentales, pero algunas personas con discapacidad intelectual psíquica- precisan más o menos apoyos para ejercitar sus derechos, respetando su voluntad y preferencias, evitando conflictos de intereses y la influencia indebida, siendo proporcionales y adaptados a las circunstancias de la persona ${ }^{59}$.

Las medidas de apoyo han de tener como objetivo primordial su progresiva reducción hasta que sean las mínimas e imprescindibles para garantizar la preservación de sus derechos (art. 2.4 Convención). Se han de establecer mecanismos de revisión periódica de la autonomía de la persona con discapacidad para en su caso se reduzcan los apoyos y su ampliación de la autonomía individual. Las medidas de apoyo serán las mínimas e imprescindibles para el ejercicio de la capacidad jurídica de la persona con discapacidad (art. 5.4 y 12.3 Convención), serán proporcionales y adaptadas a las circunstancias de la persona (art. 12.4 Convención).

\section{II.5. La incidencia del artículo 12 de la convención de 2006 en la teoría clásica de la capacidad de la persona según la jurisprudencia del T.S.}

La Jurisprudencia, hasta hace poco, no había tenido en cuenta la diversidad que trae consigo la discapacidad. Durante mucho tiempo el Tribunal Supremo, sin una contemplación singularizada de la discapacidad, ha venido declarando la incapacitación total con el nombramiento de tutor sin atender a las necesidades concretas de cada persona con discapacidad intelectual.

\footnotetext{
${ }^{57}$ DE ASIS ROIG, R., BARRANCO AVILÉS, Ma del C., CUENCA GOMÉZ, P. y PALACIOS RIZZO, A., Algunas reflexiones generales sobre el impacto de la Convención Internacional de los Derechos de las personas con Discapacidad en el Derecho español, en "Estudios sobre el impacto de la Convención Internacional sobre los derechos de las personas con discapacidad en el Ordenamiento Jurídico español” (Ed. Cuenca Gómez, P.), Dykinson, Madrid, 2010, p. 28 y ss.

58 SEOANE RODRÍGUEZ, J.A., La Convención de la ONU sobre los derechos de la persona con discapacidad: perspectiva jurídica, En "Siglo Cero. Revista Española sobre discapacidad intelectual", Vol. 42, $\mathrm{n}^{\mathrm{o}} 237,2011$, pp. 28 y 29, aboga por la necesidad de revisar los procesos de modificación de la capacidad de obrar y los modelos de representación y guarda de las personas con discapacidad, dirigiéndose hacia modelos más flexibles que permitan apoyos puntuales e individuales, y no necesariamente permanentes, que refuercen instituciones ya existentes, como las de guarda de hecho, e incorporen nuevas figuras como la asistencia. PEREÑA VICENTE, M. La transformación de la guarda de hecho en el anteproyecto de Ley, Revista de Derecho Civil, vol. V, núm. 3, julio-septiembre, 2018, pp. 61 a 83.
}

${ }^{59}$ Art. 12.4 de la Convención de 2006. 
Sin embargo, tras la Convención de 2006 y ante la inacción del legislador ha sido la jurisprudencia, la que ha evolucionado través de una interpretación "pro-Convención de las normas codificadas vigentes, en la medida en que éstas lo permitan"60.

Algo empezó a cambiar con la Sentencia del TS de 29 de abril de 2009 con la que se comienza el camino hacia la personalización de las medidas de protección atendiendo a las necesidades de las personas con discapacidad intelectual, procurando adaptar el vigente sistema de protección del Código Civil a la filosofía de la Convención, buscando la compatibilidad de ambos ${ }^{61}$.

En esa sentencia, ante las dudas en lo relativo al procedimiento de modificación de la capacidad de obrar o de determinación de apoyos ${ }^{62}$, regulado en la Ley de Enjuiciamiento Civil de 2000 y su adecuación a lo dispuesto en la Convención de 2006, el Ministerio Fiscal argumentó ante el Tribunal Supremo ${ }^{63}$-que respondió en la susodicha Sentencia de 29 de abril de 200964-, en síntesis, lo siguiente ${ }^{65}$ :

- La Convención de 2006 confiere a nuestro modelo rehabilitador únicamente carácter residual, ya que, en este modelo, la configuración tradicional de la incapacitación puede suponer una limitación excesiva, e incluso absoluta de la capacidad de obrar, en aquellas personas con alguna deficiencia intelectual, impidiéndoles la realización de actos de carácter personal y patrimonial, suponiendo en la práctica, un modelo de sustitución en la toma de decisiones.

- El modelo de la Convención colisiona con la figura tradicional de la incapacitación -con constitución de la tutela-, como modelo sustitutivo de la capacidad de obrar, y obliga a adoptar un sistema de apoyos que se proyecte sobre las circunstancias concretas de la persona, el acto o negocio a realizar.

${ }^{60}$ GARCÍA RUBIO, M M . P., La necesaria y urgente adaptación del Código Civil español al artículo 12 de la Convención de Nueva York sobre los derechos de las personas con discapacidad, Anales de la Academia Matritense del Notariado, T. 58, no 1, 2018, pp.143 a 192, en concreto p.160.

${ }^{61}$ RJ 2009/2901.

62 Según utilicemos la terminología utilizada por la Ley 1/2009 o por la Ley 26/2011.

63 “....La curatela, reinterpretada a la luz de la Convención, desde el modelo de apoyo y asistencia y el principio del superior interés de la persona con discapacidad, parecen la respuesta más idónea. De un lado porque ofrece al Juez, el mecanismo más eficaz para determinar las medidas de apoyo para que las personas con discapacidad puedan ejercer su capacidad de obrar. De otro, porque la curatela ofrece un marco graduable y abierto, en función de las necesidades y las circunstancias de apoyo en la toma de decisiones. Ya no se trata de hacer un traje a medida de la persona con discapacidad, sino de hacer los trajes a medida que hagan falta."

${ }^{64}$ STS 282/2009, de 29 de abril de 2009, (RJ 2009, 2901), Sala Primera, de lo Civil, Ponente: Encarnación Roca Trias, INCAPACITACIÓN. La configuración tradicional de la incapacitación, desde una concepción que tiene como base el modelo médico, puede suponer una limitación excesiva e incluso absoluta de la capacidad de obrar, en aquellas personas con alguna deficiencia física, intelectual o psicosocial, impidiéndoles la realización de actos de carácter personal y patrimonial o suponiendo en la práctica, un modelo de sustitución en la toma de decisiones. La Convención tanto en su Preámbulo como en su estructura normativa, adopta el modelo social y el principio de no discriminación, colisionando con la figura tradicional de la incapacitación, como mecanismo sustitutivo de la capacidad de obrar, y obliga a "adoptar" una nueva herramienta basada en un sistema de apoyos que se proyecte sobre las circunstancias concretas de la persona, el acto o negocio a realizar".

${ }^{65}$ La referencia la tomo de GARCIA PONS, A., El artículo 12 de la Convención de Nueva York de 2006 sobre los Derechos de las Personas con Discapacidad y su impacto en el Derecho Civil de los Estados signatarios: el caso de España, Anuario de Derecho Civil, t. LXVI, 2013, fasc. I, pp. 76 y ss. Para profundizar en el tema y del mismo autor, vide: Las personas con discapacidad en el ordenamiento jurídico español. La Convención internacional del 13 de diciembre de 2006, Ed. Universitaria Ramón Areces, Madrid, 2008. 
- La Convención unifica la capacidad jurídica y de obrar en un todo inseparable, proporcionando los mecanismos de apoyo adecuados, lo que asegura a la persona con discapacidad, su plena capacidad para crear, modificar o extinguir relaciones jurídicas, y

- restringe el instrumento de la incapacidad si afecta a la anulación de la capacidad de obrar.

Y concluye diciendo que la Convención propugna el cambio del modelo de sustitución en la toma de decisiones por el nuevo modelo de apoyo o asistencia en la toma de decisiones, aunque deja la determinación del apoyo y su extensión a la regulación del Derecho interno.

El Tribunal Supremo, en la susodicha sentencia, lejos de recoger estos argumentos del Ministerio Fiscal, declaró ajustado a la Constitución Española y a la Convención del 2006 el proceso español de incapacitación ya que se trata de una medida de protección a favor de la persona que no discrimina, debido a las específicas características que en ésta se presentan y que hacen necesaria aquella medida. Reconoció también que el sistema de protección de nuestro Código Civil se debe adaptar a las conveniencias y necesidades de protección de la persona afectada, constituyendo una situación revisable ${ }^{66}$, según la evolución de la causa que ha dado lugar a tomar la medida de protección: en consecuencia, la figura de representación general que supone la tutela, que ha sido durante mucho tiempo la figura más utilizada tras el denominado procedimiento de incapacitación, será progresivamente sustituida por la curatela como figura más respetuosa con la Convención de 2006.

El Tribunal Supremo, atendiendo a la propia doctrina de la Sala Primara y a la Sentencia del Tribunal Constitucional 174/2002, de 9 de octubre, ha determinado en su fundamento séptimo de la Sentencia de 29 de abril de 2009, que "el sistema de protección establecido en el Código Civil sigue vigente, aunque con la lectura que se propone:

$1^{\circ}$.- Que se tenga siempre en cuenta que el incapaz sigue siendo titular de sus derechos fundamentales y que la incapacitación es sólo una forma de protección. Esta es la única posible interpretación del art. 200 CC y del art. 760 de la LEC.

$2^{\circ}$.- La incapacitación no es una medida discriminatoria porque la situación merecedora de la protección tiene características específicas y propias. Estamos hablando de una persona cuyas facultades intelectivas y volitivas no le permiten ejercer sus derechos como persona porque le impiden autogobernarse. Por tanto, no se trata de un sistema de protección de la familia, sino única y exclusivamente de la persona afectada."

En definitiva, una interpretación adecuada de la regulación establecida en la Convención de 2006 no excluye el sistema de protección establecido en nuestro Código Civil ya que "la incapacitación es sólo una forma de protección de los discapaces, que por ello mismo no es una medida discriminatoria, sino defensora y no vulnera la dignidad de la persona" ya que estamos hablando de una persona cuyas facultades intelectivas y volitivas no le permiten ejercer sus derechos como persona porque le impiden autogobernarse ${ }^{67}$.

${ }^{66}$ PALLARÉS NEILA, J., La revisión de las Sentencias dictadas en el nuevo procedimiento de provisión de apoyos, Revista de Derecho Civil, vol. V, núm. 3, julio-septiembre de 2018, pp. 153-171.

${ }^{67}$ Básicamente están de acuerdo con la doctrina establecida en esta Sentencia del Tribunal Supremo, DE PABLO CONTRERAS, P. Comentario de la Sentencia del Tribunal Supremo 282/2009, de 29 de abril de 2009, (RJ 2009, 2901). La incapacitación en el marco de la Convención sobre los derechos de las personas con discapacidad. En "Comentarios a las Sentencias de unificación de doctrina (Civil y Mercantil), Vol. 3, 2009, 
En las posteriores sentencias el Tribunal Supremo reinterpreta la curatela a la luz de la Convención de 2006, desde el modelo de apoyo y de asistencia, así como desde el principio del superior interés de la persona con discapacidad ${ }^{68}$, poniéndose énfasis en la personalización de las medidas de protección ${ }^{69}$.

En consecuencia, en esta línea de la Convención, la Jurisprudencia evoluciona y determina que, en general, resulta determinante que se aplique una curatela más flexible, salvo para los actos personalísimos-matrimonio, testamento, en la medida que tenga capacidad natural para entender y querer dichos actos-, y en su caso, se acudirá a la tutela, pero limitada a casos más excepcionales, reservándola para los casos de incapacitación total ${ }^{70}$.

(Dir. Yzquierdo Tolsada, M,), Dykinson, Madrid, 2010, pp. 555 y ss. quien concluye que nuestro sistema legal vigente interpretado conforme a la Constitución y a la Declaración Universal de los Derechos Humanos, no vulnera la Convención de Nueva York de 2006, especialmente p. 579. ESCRIBANO TORTEJADA, P. El patrimonio protegido de la persona con discapacidad, Ed. Tirant lo Blanch, Valencia, 2012, pp. 43 y ss. PÉREZ DE ONTIVEROS BAQUERO, C., Comentario a la Sentencia de 29 de abril de 2009, Cuadernos Civitas de Jurisprudencia Civil, $\mathrm{n}^{\circ}$ 82, enero-abril de 2010, especialmente pp. 341 a 343, en las que se inclina por el criterio de que el Derecho español cumple con la Convención de 2006. RODRIGUEZ ESCUDERO, M. V., La incapacitación y el respeto a los derechos de las personas discapacitadas: el interés de la persona protegida, en "La encrucijada de la incapacitación y la discapacidad". Comunicaciones. (Dir. Pérez de Vargas Muñoz, J. y Coord. Pereña Vicente, M.), La Ley, Las Rozas, Madrid, 2011, pp. 373 y ss. Por otro lado, critican la Sentencia susodicha por considerar que está anclada en el modelo médico o rehabilitador y no haber entendido bien el modelo social, ÁLVAREZ LATA, N. Y SOANE RODRÍGUEZ, J.A., El proceso de toma de decisiones de la persona con discapacidad. Una revisión de los modelos de representación y guarda a la luz de la Convención sobre Derechos de la persona con discapacidad. Derecho Privado y Constitución, n 24, enero-diciembre 2010, pp. 46 y ss.

${ }^{68}$ Entre otras, SSTS de 21 de diciembre de 2011, de 17 de julio de 2012; STS de 11 de octubre de 2012, RJ 2012, 9713, referida a la sujeción a curatela reinterpretada a la luz de la Convención sobre los derechos de las personas con discapacidad; STS de 24 de julio de 2013, RJ 2013, 3948, se refiere también a la curatela, procedencia y aplicación, a la luz de la Convención de 2006 desde un modelo de apoyo y de asistencia según el principio del superior interés de la persona con discapacidad que "manteniendo la personalidad se requiere un complemento de capacidad"; 30 de junio de 2014, RJ 2014,4930; 1 de julio de 2014, RJ 2014, 4518, pone acento en la graduación de la incapacitación y la necesaria flexibilidad de la medida con la adaptación a la concreta necesidad de protección de la persona con discapacidad, prefiriendo el TS la curatela como fórmula de apoyo; 30 de septiembre de 2014, RJ 2014, 4864; 27 de noviembre de 2014, RJ 2014, 6032; 13 de mayo de 2015, RJ 2015, 2023 declara que "El juicio de incapacidad no puede concebirse como un conflicto de intereses privados y contrapuestos entre dos partes litigantes, que es lo que, generalmente caracteriza a los procesos civiles, sino como el cauce adecuado para lograr la finalidad perseguida, que es la real y efectiva protección de la persona discapacitada mediante el apoyo que pueda necesitar para el ejercicio de su capacidad jurídica"; 14 de octubre de 2015, RJ 2015,4755; 20 de octubre de 2015, RJ 2015, 4900; 4 de noviembre de 2015, RJ 2015,5138; 17 de noviembre de 2015, RJ 2015,5726; 3 de junio de 2016, RJ 2016, 2311; 11 de octubre de 2017, RJ 2017, 4290; 27 de septiembre de 2017, RJ 2017, 5913; 8 de noviembre de 2017, RJ 2017, 4760; 19 de febrero de 2020, RJ 2020, m 392.

${ }^{69}$ Sobre la evolución jurisprudencial GUILARTE MARTÍN-CALERO, C., La reinterpretación jurisprudencial de los sistemas de protección a la luz de la Convención de Nueva York: el nuevo paradigma de la Sala Primera, en "Estudios y comentarios jurisprudenciales sobre discapacidad", (Dir. Guilarte Martín-Calero, C.), Aranzadi, Navarra, 2016, pp. 59 a 104. De la misma autora, La contribución de la jurisprudencia del Tribunal Supremo al diseño del nuevo sistema de protección previsto en el anteproyecto de Ley por la que se reforma la legislación civil y procesal en materia de discapacidad de 21 de septiembre de 2018, en "Claves para la adaptación del ordenamiento jurídico privado a la Convención de Naciones Unidas en materia de discapacidad”, (Dir. De Salas Murillo, S y Mayor Del Hoyo, M.V.), Tirant lo Blanch, Valencia, 2019, 361 a 398.

70 STS de 10 de octubre de 2013, RJ 2013, 7804. Para GARCÍA RUBIO, Mª. P., La necesaria y urgente adaptación del Código Civil español al artículo 12 de la Convención de Nueva York sobre los derechos de las personas con discapacidad, Anales de la Academia Matritense del Notariado, T. 58, no 1, 2018, pp.143 a 192, 
El TS en la sentencia de 16 de mayo de 2017, expone claramente que "el sistema de apoyos a que alude la Convención está integrado en el Derecho español por la tutela y la curatela, junto a otras figuras, como la guarda de hecho y el defensor judicial... La tutela es la forma de apoyo más intensa que puede resultar necesaria cuando la persona con discapacidad no pueda tomar decisiones en los asuntos de su incumbencia, ni por si misma ni tampoco con el apoyo de otras personas... Pero en atención a las circunstancias personales puede ser suficiente un apoyo de menos intensidad que, sin sustituir a la persona con discapacidad, le ayude a tomar las decisiones que le afecten. En el sistema legal, está llamada a cumplir esta función la curatela, concebida como un sistema mediante el cual se presta asistencia, como un complemento de capacidad, sin sustituir a la persona con discapacidad"71.

La STS de 11 de octubre de 2017, recordando el art. 12 de la Convención de 2006 y la Jurisprudencia del propio Tribunal Supremo que compatibiliza el sistema del Código Civil con el mentado precepto de la Convención de Nueva York ${ }^{72}$, persiste en la necesidad de confeccionar un traje a medida en cada llamado procedimiento de incapacitación. En el caso concreto, al TS le parece desproporcionado someter al interesado a tutela ya que lo que precisa esa persona es el seguimiento del tratamiento prescrito por el médico, afección de salud que puede afectar al aspecto patrimonial, pero sin que se justifique su total privación de capacidad de obrar, razón por la cual estima que ha de establecerse la curatela ${ }^{73}$.

La STS de 8 de noviembre de 2017 se refiere a la controversia sobre la designación de una tutela como medida de apoyo para una mujer que sufría de una enfermedad mental cuyo alcance según la sentencia recurrida requería de funciones de representación en el ámbito sanitario y de mera asistencia en el ámbito patrimonial. Al respecto dice la susodicha sentencia que "la necesidad de atender a las circunstancias personales del incapacitado puede aconsejar que, limitada la capacidad de una persona, necesite la función de asistencia para determinados actos que pueda hacer por sí, pero no sólo, y la función de representación para otros... La doctrina del Código Civil admite una curatela con funciones de representación ... Lo que importa, en esencia, es dotar al incapacitado de un sistema de guarda flexible adoptado a su concreta situación de necesidad de representación en unos casos y mera asistencia en otros, con independencia del nombre que se asigne al cargo, a la institución tutelar, en sentido amplio". Por todo ello el TS considera que el apoyo que precisa la interesada es el que le brinda la curatela -y no el de la tutela-, en "el ámbito personal un apoyo que complemente su capacidad en el ámbito médico-sanitario, en todo lo relativo a la necesidad de ingresos hospitalarios, seguimiento de tratamiento, asistencia a las citas médicas de control de su medicamento" 74 .

El TS constata que para que sean eficaces las medidas de protección se hace necesaria la valoración concreta de cada persona discapacitada, a fin de realizarle un traje a medida en los apoyos

en concreto p.159, la Jurisprudencia ha conseguido allanar el camino a favor de la curatela como figura más flexible y favorable al ejercicio de la capacidad jurídica de las personas con discapacidad.

${ }^{71}$ STS 298/2017, de 16 de mayo, RJ 2017, 2207. Se trataba de un caso en que tanto la sentencia de primera como de segunda instancia habían sometido a la persona con discapacidad a tutela. El TS se aparta de ese parecer, por entender que la situación del afectado no es la propia de una discapacidad total en la que la persona se encuentra privada de toda capacidad de decisión de modo que otro deba decidir en su lugar. Por eso afirma que la curatela es una institución más flexible que se caracteriza por su contenido de asistencia y supervisión, no por el ámbito personal o patrimonial, o por la extensión de actos en lo que esté llamada a prestarse. La curatela puede ser un apoyo en la esfera personal o en la patrimonial, o en ambas, según lo requiera en cada caso la protección de la persona.

72 Especialmente la STS de 1 de julio de 2014, RJ,2014, 4518.

${ }^{73}$ STS de 11 de octubre de 2017RJ 2017, 4290.

${ }^{74}$ STS 597 de 8 de noviembre de 2017, RJ, 2017, 4745. 
que necesita. En este sentido la STS de 7 de marzo de 2018 hace hincapié en la necesidad de respetar la autonomía e independencia individual de la persona con discapacidad confeccionándole unos "apoyos a la medida" para lo que se exige "la colaboración de todas las partes implicadas en el conocimiento de la persona afectada por alguna anomalía física o psíquica, lo que se traduce en lo procesal no solo en una aportación de los datos y pruebas que sean necesarias adoptar para evaluar correctamente su situación y la mayor o menor reversibilidad de la insuficiencia que le afecta, sino en la determinación de las medidas de apoyo que sean necesarias en atención a su estado y las personas que deben prestarlas siempre en beneficio e interés del discapaz, respetando en la esfera de autonomía e independencia individual que presente en orden a la articulación y desarrollo de estas medidas para la adopción o toma de decisiones" 75 .

Por último, la STS 2018-RJ 2018, 1090- referida a la acción de impugnación de los testamentos ${ }^{76}$, otorgados con 19 años de diferencia, por una mujer con discapacidad intelectual moderada, respecto de la cual se había dictado dos años después del primer testamento una sentencia de incapacitación en la que se declaraba que la señora era incapaz para la administración de sus bienes y quedaba sometida a curatela, si bien la incapacidad estaba referida a los actos de disposición de sus bienes...la limitación de la capacidad de obrar para realizar actos de disposición sin intervención del curador no comprende los actos de disposición mortis causa, por lo que el TS sostuvo, entre otros razonamientos, la validez de los testamentos, basándose en la presunción general de capacidad expresada en el art. $662 \mathrm{CC}$, en el dato de que tratándose de un acto personalísimo, ni el tutor ni el curador pueden otorgar testamento por representación o asistir al testador en su otorgamiento y en que para juzgar la capacidad para testar ha de estarse al tiempo del otorgamiento (Art. 665 y 666 del $\mathrm{CC})$.

\section{II.6. Conclusiones sobre las posiciones doctrinales y la postura de la jurisprudencia}

De lo expuesto hasta aquí, pueden extraerse algunas conclusiones ${ }^{77}$. En primer lugar, en la doctrina existen partidarios de conservar las instituciones tutelares vigentes -tutela, curatela, defensor judicial y guardador de hecho- pero adaptándolas en su régimen jurídico a la Convención de 2006, desarrollando la curatela como sistema de asistencia principal, adaptado a cada caso particular de la persona con discapacidad, con revisiones periódicas y con atención especial a la propia persona, sus preferencias e intereses ${ }^{78}$.

\footnotetext{
75 STS de 7 de marzo de 2018, RJ 2018, 934. La STS 145 del 15 de marzo de 2018, RJ 2018, 1478 sobre la nulidad o validez de un matrimonio contraído por una persona diagnosticada de alzheimer, entiende que el derecho a contraer matrimonio es un derecho fundamental derivado de la dignidad del ser humano. Estima que la integridad del consentimiento matrimonial está salvaguardada en nuestro Derecho por diversas normas entre otras, los artículos 45, 73.1 y 56 todos del CC- que evidencian que las deficiencias psíquicas no impiden, por sí mismas, la celebración del matrimonio válido. Apoyándose el TS en el art. 56 CC, considera que el matrimonio en cuestión es válido.

${ }^{76}$ RJ 2018, 1090.

77 Con GARCÍA PONS, A., El artículo 12 de la Convención de Nueva York de 2006 sobre los Derechos de las personas con discapacidad y su impacto en el Derecho Civil de los Estados signatarios: el caso de España, Anuario de Derecho Civil, t. LXVI, 2013, fasc. I, pp. 140 a 143.

${ }^{78}$ BERROCAL LANZAROT, A.I., La curatela como institución de protección en el marco de la Convención sobre los derechos de las personas con discapacidad, Revista Crítica de Derecho inmobiliario núm. 732, julioagosto 2012, pp. 235 a 2478. DE PABLO CONTRERAS, P. DE PABLO CONTRERAS, P. Comentario de la Sentencia del Tribunal Supremo de 29 de abril de 2009. La incapacitación en el marco de la Convención sobre los derechos de las personas con discapacidad. En "Comentarios a las Sentencias de unificación de
} 
Desde esta orientación se pone el acento más "en la seguridad jurídica y en la protección del tráfico jurídico. Es la resolución judicial la que declara la incapacitación... y el grado de ésta así como el órgano de protección: tutela o curatela, art. 760 LEC, si bien la primera no está prevista en la Convención -supone la sustitución de la persona incapacitada - no así la curatela que de acuerdo con la Convención, art. $12.5^{\circ}$, se la configura como un sistema de apoyo a través del nombramiento del curador que asista-por ello su denominación de asistente-como complemento de la capacidad de la persona... Sin embargo, como sistema de protección no cabe abandonar el procedimiento que legislan tanto el Código Civil, artículos 199 y 200 CC, como la Ley de Enjuiciamiento Civil, art. 757 a 762, en cuanto a su extensión y posible cambio de figura protectora pero también modificación del alcance de la sentencia, art. 761 LEC. A favor de su permanencia se aboga desde dos postulados: Bien que la Convención de Nueva York de 13 de diciembre se refiere exclusivamente a la discapacidad que requiere curatela como regla general adaptada a cada persona discapaz, pero no trata de la incapacidad para lo cual la incapacitación y la tutela ${ }^{79}$ sea lo más adecuado en especial para aquellas personas que no pueden defenderse por sí mismas. O como puso de manifiesto la reiterada STS ${ }^{80}$ de 29 de abril de 2009 al añadir que la incapacitación no es algo rígido, sino flexible en cuanto que debe adaptarse a la concreta necesidad de protección, y que se plasma en la graduación de la incapacitación debiendo incluso valorar su permanencia de manera restrictiva para cuando la ausencia de entendimiento y voluntad en la persona no le hace posible ejercer su autonomía ni ninguna otra forma de autogobierno" $"$.

doctrina (Civil y Mercantil), Vol. 3, 2009, (Dir. Yzquierdo Tolsada, M,), Dykinson, Madrid, 2010, especialmente las pp.562, 575 Y 579. PÉREZ DE ONTIVEROS BAQUERO, C., Comentario a la Sentencia de 29 de abril de 2009, Cuadernos Civitas de Jurisprudencia Civil, no 82, enero-abril de 2010, especialmente pp. 341, 342, 343, y ss. RAMS ALBESA, J. Hombre y persona. Personalidad. Capacidad e incapacidad. Discapacidad y vejez (Reflexión sobre estos conceptos jurídicos esenciales, de ordinario tratados como lugares comunes), Revista Crítica de Derecho Inmobiliario, enero-febrero 2011, n. 723, pp. 211 a 296, especialmente en las pp. 252, 256, 283, 287 y 290. SERRANO GARCÍA, I., Autotutela. El artículo 223.II del Código Civil y la Convención de Nueva york sobre los derechos de las personas con discapacidad de 2006, Tirant lo Blanch, Valencia 2012.

79 Aboga por la desaparición de la incapacitación CARBONNIER, J., Droit Civil I, Les personnes. Incapacite, Ed. PUF, Themis, 17 Ed., Paris, 2000, pp. 179 y ss. "si la institución misma de la incapacitación no está llamada a desaparecer, su permanencia por una parte parece, contradecir la filosofía de los derechos del hombre y por otra, declarar incapacitado a una persona es una injuria total". En cuanto a la tutela como institución tutelar en cuanto significa sustitución de ésta por el tutor se aboga por una regulación más restrictiva por GARCÍA RUBIO, M ${ }^{a}$. P., La persona en el Derecho civil. Cuestiones permanentes y algunas otras nuevas, Teoría/Derecho, Revista de pensamiento jurídico. Sobre el concepto de persona, Tirant lo Blanch, Valencia, 2013, p. 93, si bien atendiendo aquellos supuestos en los que la carencia total de autogobierno le impide tanto desde el aspecto personal como patrimonial gobernarse por sí mismo.

${ }^{80}$ RJ 2009/2901.

${ }^{81}$ TORRES GARCÍA, T.F., La incapacitación: Don Federico de Castro al momento actual, en "Glosas sobre Federico de Castro, (Dir. Díez Picazo, L.), Aranzadi, Navarra, 2015, pp. 398-408, concretamente la cita es de las páginas 407 y 408 . En la nota 49 de esta última página, la autora cita la Sentencia de 18 de septiembre de 2014, del TEDH/2014, 57. Caso Ivinomic. Croacia: “...Estimando que, a la hora de incapacitar legalmente a título parcial, el procedimiento seguido no fue conforme con las garantías del artículo 8 del Convenio: Por la manera en que fue llevado el procedimiento: que cuando las personas padecen discapacidades mentales se exige que garanticen a estas personas, un representante independiente".

Afirma en las pp. 396 y 397 que estamos en un momento en el que se intenta sustituir el vigente sistema...y se quiere pasar página de este sistema que centra en el poder judicial la incapacitación, así como del órgano de protección de la tutela, reservándose ésta para la adecuada protección del enfermo mental permanente, apostando por la curatela como regla, pero en una determinada extensión y límites siempre revisables. 
En segundo lugar, existe otro sector doctrinal ${ }^{82}$ que propugna seguir un modelo basado en medidas de apoyo, y con un responsable de las mismas -curador o persona de apoyo-, graduando su intensidad en función de las características individuales de la persona, que se atienda a sus preferencias y a las circunstancias del caso concreto, que tengan carácter temporal y existan revisiones periódicas, todo lo cual tiende a proporcionar la debida autonomía de la persona con discapacidad. Se reservaría el apoyo intenso (de representación legal, tutela) únicamente para supuestos graves y extremos de discapacidad, perdurable en el tiempo, en el caso de que la persona discapacitada que de ningún modo pueda actuar o valerse por sí misma o incluso, en ciertos casos, no pueda ni manifestar su voluntad, pero aún en estos casos más severos, se ha de procurar un apoyo personalizado, de manera que la persona con discapacidad pueda desarrollar su autonomía.

Si hasta ahora el ámbito de representación y asistencia legal viene determinando la posible actuación individual de la persona con discapacidad, con el cambio legislativo previsto, el ámbito del ejercicio de la capacidad jurídica de la persona, de su autonomía personal, delimitará la concreta actuación de los apoyos que se establezcan.

Ahora bien, tras la Convención de 2006 y ante la inacción del legislador durante un tiempo, ha sido la jurisprudencia, como nos recuerda GARCIA RUBIO, "la encargada provisionalmente de hacer el tránsito" a través de una interpretación pro-Convención de las normas codificadas vigentes, al menos cuando éstas o en la medida en que éstas lo permiten" $" 83$.

\section{El cambio de sistema de protección de la discapacidad intelectual en nuestro Código Civil}

Tras la inclusión de la Convención de Nueva York el 15 de diciembre de 2006, en nuestro Ordenamiento Jurídico, se han de realizar algunas consideraciones en relación con el ejercicio de la capacidad jurídica ${ }^{84}$.

Tradicionalmente venimos diferenciando entre capacidad jurídica y capacidad de obrar. La primera es igual para todas las personas físicas. La segunda varía dependiendo de la situación jurídica de cada una. En el modelo vigente hasta la Ley 8/2021, de 2 de junio, por la que se reforma la

82 ALVAREZ LATA, N., Y SEOANE RODRÍGUEZ, J.A., El proceso de toma de decisiones de la persona con discapacidad. Una revisión de los modelos de representación y guarda a la luz de la Convención sobre los Derechos de las personas con discapacidad, Derecho Privado y Constitución, núm. 24, enero-diciembre de 2010, pp. 11 a 66. GETE-ALONSO Y CLAERA, Ma . C., Capacidad de obrar y ejercicio de los derechos de la personalidad de la persona con discapacidad, en "Estudios sobre Dependencia y discapacidad" (Dir. García Garnica, Ma del C.) Aranzadi, Navarra, 2011, pp. 41 a 98. RIVERA ÁLVAREZ, J. Mª Notas sobre el apoyo a la autodeterminación de la persona incapacitada en el Código Civil a partir de la Convención de las Naciones Unidas sobre derechos de las personas con discapacidad, en "Encrucijada de la incapacitación y la discapacidad, (Dir. Pérez de Vargas Muñoz, J. y Coord. Pereña Vicente, M.), La Ley, Madrid, 2011, pp. 347 a 372, especialmente pp.349 a 351, insiste en que lo que hay que graduar son los apoyos y no tanto la capacidad, apoyos para la toma libre de decisiones de las personas con discapacidad que los precisen.

83 GARCÍA RUBIO, Ma . P., La necesaria y urgente adaptación del Código Civil español al artículo 12 de la Convención de Nueva York sobre los derechos de las personas con discapacidad, Anales de la Academia Matritense del Notariado, T. 58, no 1, 2018, pp.143 a 192, en concreto p.160.

${ }^{84}$ El Comité para los Derechos de las personas con discapacidad de naciones Unidas, el 11 de octubre de 2011, tras examinar las acciones desarrolladas por España, recomendaba "que revise las leyes que regulan la guarda y la tutela y que tome medidas para adoptar leyes y políticas por las que se reemplacen los regímenes de sustitución en la adopción de decisiones por una asistencia para la toma de decisiones que respete la autonomía, la voluntad y las preferencias de las personas". http://www.fsc.ccoo.es/771f2daa6289ab7f2ff656e64bf4d331000050.pdf. 
legislación civil y procesal para el apoyo a las personas con discapacidad en el ejercicio de su capacidad jurídica, "nadie puede ser declarado incapaz sino por sentencia judicial en virtud de las causas establecidas en la Ley" (art. 199 CC), siendo causas de incapacitación "las enfermedades o deficiencias persistentes de carácter físico o psíquico que impidan a la persona gobernarse por sí misma" (art. 200 CC). Por tanto, una persona con esas enfermedades o deficiencias, tras el correspondiente proceso judicial, sufre una capitis deminutio hasta que se rehabilite para el ejercicio de sus derechos por sí misma. Mientras tanto, las decisiones de la vida de esa persona, a la que se le ha modificado su capacidad, quedan sujetas a un tercero -tutor o curador-. La pretensión es que el tutor o el curador, actúe en interés de la persona que tiene modificada su capacidad de obrar, incluso sin contar con ella. Las restricciones en la capacidad de la persona, en su ejercicio autónomo en su capacidad de obrar, se justifican en salvaguardar los intereses del sujeto a las instituciones de guarda.

Con la Convención de 2006, todas las personas, prima facie, son iguales en capacidad jurídica y en su ejercicio, lo cual tiene amplias y profundas consecuencias sobre todos los aspectos del Derecho civil - y no solamente sobre él-. En este contexto, la modificación de la capacidad de una persona resulta restrictiva de sus derechos y libertades puesto que se basa en la sustitución por el cargo tuitivo en la toma de decisiones.

La Convención del 2006 al referirse al ejercicio de la capacidad jurídica por las personas con discapacidad, exige que se proporcionen mecanismos de apoyo para garantizar a esas personas el pleno ejercicio de su capacidad jurídica para realizar actos o negocios jurídicos, restringiendo al máximo la sustitución por un tercero en el ejercicio de su capacidad jurídica.

Tras la Convención de Nueva York -teniendo presente lo dispuesto en su art. 12-, se impone el facilitar la toma de las propias decisiones de las personas con discapacidad intelectual en el ejercicio de su capacidad jurídica mediante un modelo de apoyos que puedan necesitar para superar las dificultades que persistan ${ }^{85}$. No se trata de que el tercero que apoya sustituya a la persona con discapacidad, sino de que aquel ponga a disposición de ésta su apoyo para que pueda tomar sus propias decisiones. Si esto no resultase finalmente posible, se precisará un sistema de apoyo adaptado a la situación concreta de la persona con discapacidad a efectos del ejercicio de su capacidad jurídica. De esta manera, cada persona con discapacidad intelectual recupera su protagonismo y participa en el proceso de toma de decisiones sin cercenarse su capacidad de obrar. En suma, a la persona con discapacidad intelectual se le reconoce su capacidad de asumir responsabilidades tomando las decisiones que le afectan, con el apoyo que sea necesario en cada momento, como protagonista activo en el desarrollo de su proyecto vital.

En general, la intervención del tercero que apoya no tiene por objeto decidir por la persona con discapacidad intelectual sustituyéndola en la toma de decisiones, sino que va dirigida a ayudar a ésta a decidir, acompañándola en la decisión, decidiendo con la persona y para la persona con discapacidad. Se busca el respeto de la libertad y autonomía de la persona. Así pues, en el modelo de apoyo descrito se trata de facilitar a las personas con discapacidad psíquica, los medios necesarios, incluida la asistencia de terceros, para que pueda desarrollar su libertad y autonomía personal.

\footnotetext{
${ }^{85}$ Se viene reclamando una actualización del Derecho civil mediante la reforma integral y coordinada del Código Civil y de las ramas del Ordenamiento Jurídico privado afectadas, de carácter sustancial y procesal para garantizar el cumplimiento de lo previsto en la Convención de 2006 respecto a las personas con discapacidad, entre otros, ALCAÍN MARTÍNEZ, E., Hacia la actualización del Derecho civil conforme a la Convención Internacional de los Derechos de las personas con discapacidad. Apuntes para su reforma, en "Protección civil y penal de los menores y de las personas mayores vulnerables en España” (Coord. Andreu Martínez M.B. y Leciñena Ibarra, A.), Aranzadi, Navarra, 2018, pp. 166 a 196, en concreto en las pp. 168, 171,175, 191 y 196.
} 
Hay que reconocer que determinadas personas con discapacidad intelectual grave ${ }^{86}$, no pueden actuar por sí mismas dado que sus condiciones de querer y entender afectan a la libre determinación para gobernarse por sí mismas y valerse por sí mismas, sin que puedan manifestar su voluntad en los casos extremos. Ante esta situación, se requerirá un apoyo tal que implique la propia sustitución de la persona con discapacidad en la toma de decisiones, pero teniendo presente por el que ejerce la función tuitiva, la filosofía de vida de la persona con discapacidad en cuestión y con sus preferencias, deseos, valores, etc.

Por tanto, en consideración a todo lo expuesto, con la aprobación de la Ley 8/2021, de 2 de junio susodicha, se produce un cambio del modelo de sustitución a otro de apoyo o protección, en el que el tercero que apoya en el ejercicio de la capacidad de obrar queda en la trastienda para ocupar un primer plano, en lugar preferente, mediante las medidas de apoyo, la persona con discapacidad ya que, debido a su dignidad personal inherente a toda persona, el discapacitado ha de poder ejercer su capacidad jurídica en igualdad de condiciones con los demás ${ }^{87}$. El citado texto legal, cambia el viejo sistema de instituciones tutelares de sustitución por un modelo de apoyo y protección -de asistenciaen la toma de decisiones mediante el ejercicio de la autonomía individual de la persona con discapacidad intelectual, en la que está incluida la libertad de tomar sus propias decisiones ${ }^{88}$.

Por consiguiente, del modelo de sustitución o representación mediante la figura de la tutela ${ }^{89}$, se pasa al modelo de apoyos que se adaptarán a las necesidades de cada persona con discapacidad psíquica, facilitándole los mayores o menores apoyos requeridos, temporales o permanentes en función de sus necesidades.

Este cambio de modelo -de sustitución a un modelo de apoyo o asistencia en la toma de decisiones-, implica que la incapacidad desaparece. Se adoptarán las medidas de apoyo y protección que sean necesarias y que responderán a lo que necesita realmente esa persona discapacitada para ejercer su capacidad jurídica con la máxima plenitud posible. Ahora bien, si toda persona tiene capacidad jurídica, que abarca tanto la titularidad de los derechos como la legitimación para ejercitarlos, ¿qué ocurrirá si una persona deviene en una situación de discapacidad intelectual

\footnotetext{
${ }^{86} \mathrm{Si}$ a una persona le falta, de manera absoluta, la capacidad para tomar decisiones, la curatela, ahora más flexible asumirá las funciones representativas sobre el particular RIBOT IGUALADA, J., La nueva curatela: diferencia con el sistema anterior y perspectivas de funcionamiento, en "Claves para la adaptación del ordenamiento jurídico privado a la Convención de Naciones Unidas en materia de discapacidad”, (Dir. De Salas Murillo, S. y Mayor Del Hoyo, M.V.), Tirant lo Blanch, Valencia, 2019, pp. 251 y ss.

87 Desarrolla estas ideas, PALACIOS BARREIROS, A., El modelo social de discapacidad: orígenes, caracterización y plasmación en la Convención Internacional sobre los Derechos de las personas con discapacidad, Colección CERMI, núm. 36, Grupo editorial CINCA, Caja Madrid, 2008.

88 CUENCA GÓMEZ, P. (Coord.), Estudios sobre el impacto de la Convención Internacional sobre los Derechos de las personas con discapacidad en el Ordenamiento Jurídico español, Dykinson, Madrid, 2010; de la misma autora, La capacidad jurídica de las personas con discapacidad: el art. 12 de la Convención de la ONU y su impacto en el Ordenamiento Jurídico español, Derechos y Libertades, núm. 24, 2ª́poca, enero 2011, pp. 221 y ss., quien pone de manifiesto que no son las personas las que tienen que cambiar para poder merecer el atributo de la capacidad jurídica, sino que es ésta construcción social la que debe adaptarse a la situación de las personas con discapacidad.

${ }^{89}$ Entiende que para proteger no hace falta incapacitar, basta con adoptar la medida de asistir o representar a la persona en el ejercicio de su capacidad jurídica, GUILARTE MARTÍN-CALERO, C., La reinterpretación jurisprudencial de los sistemas de protección a la luz de la Convención de Nueva York: el nuevo paradigma de la Sala Primera, en "Estudios y comentarios jurisprudenciales sobre discapacidad”, (Dir. Guilarte Martín Calero, C.), Aranzadi, Navarra, 2016, pp. 361 a 392.
} 
quedando afectada su aptitud o idoneidad para la toma de decisiones?90 $\mathrm{Ha}$ de garantizarse que esas personas con discapacidad, que no están en condiciones de gestionar por si solas sus intereses, cuenten con medidas de apoyo en la toma de decisiones y con la protección en su beneficio, tomando en consideración sus deseos y preferencias, quedando limitada la actuación de un tercero en representación a las situaciones excepcionales que lo justifiquen ${ }^{91}$. Ante este planteamiento en el que a cada persona con discapacidad hay que buscarle apoyos necesarios para que pueda ejercer sus capacidades y una vez que la Convención 2006, forma parte de nuestro Ordenamiento Jurídico, se ha aprobado la Ley 8/2021, de 2 de junio por la se reforma la legislación civil y procesal para el apoyo a las personas con discapacidad en el ejercicio de la capacidad jurídica, disponiendo para el caso medidas de apoyo que han de adaptarse lo mejor posible a la voluntad y preferencias de la persona con discapacidad, teniendo presente la propia trayectoria vital antes de tal situación de discapacidad ${ }^{92}$.

\section{Bibliografía}

ALCAÍN MARTÍNEZ, E., "Hacia la actualización del Derecho civil conforme a la Convención Internacional de los Derechos de las personas con discapacidad. Apuntes para su reforma", en M.B. Andreu Martínez y A. Leciñena Ibarra (coord.), Protección civily penal de los menores y de las personas mayores vulnerables en España, Aranzadi, Navarra, 2018, pp. 166-196.

ALONSO PÉREZ, M., "Consideraciones en torno a la persona y su valoración jurídica. Estudios", en L. Díez-Picazo (coord.), Homenaje al Prof. José Ma. Miquel, vol. I, Thomson ReutersAranzadi, Navarra, 2014, pp. 241-268.

ALONSO PÉREZ, M., "Reflexiones sobre el concepto y valor de la persona en el 'Derecho civil de España", Anuario de Derecho Civil, vol. 36, nº 4, 1983, pp. 1117-1127.

ÁLVAREZ LATA, N. y SOANE RODRÍGUEZ, J. A., "El proceso de toma de decisiones de la persona con discapacidad. Una revisión de los modelos de representación y guarda a la luz de la Convención sobre Derechos de la persona con discapacidad", Derecho Privado y Constitución, n 24, 2010, pp. 11-66.

\footnotetext{
${ }^{90}$ Qué ocurrirá cuando las personas con discapacidad contraten sin las medidas de apoyo, el contrato será anulable, sobre este aspecto vide, entre otros, a CARRASCO PERERA, A., Discapacidad personal y estabilidad contractual. A propósito del Anteproyecto de Ley presentado por el Ministerio de Justicia para la reforma de la Legislación civil en materia de discapacidad. Publicaciones Jurídicas. Centro de Estudios de Consumo, 2018, pp. 1 y ss., en http://centrodeestudiosdeconsumo.com,12 de octubre de 2018, en cuya p. 5 entiende que la patología del sistema propuesto reside en "que un contrato pueda ser anulable por no respetarse las medidas de apoyo no conectadas con el consentimiento y que un contrato pueda ser anulable a pesar de que estas han sido observadas".

${ }^{91}$ Sobre estos aspectos vide DE AMUNÁTEGUI RODRÍGUEZ, C., El protagonismo de la persona con discapacidad en el diseño y gestión del sistema de apoyo, en "Claves para la adaptación del ordenamiento jurídico privado a la Convención de Naciones Unidas en materia de discapacidad (Dir. Salas Murillo, S. y Mayor del Hoyo, M. V.), Tirant lo Blanch, 2019, Valencia, pp. 125 y ss.

${ }^{92}$ La modificación del Libro I del Código Civil en lo relativo al ejercicio de la capacidad pasa por la exigencia de proporcionalidad y adecuación de las medidas de apoyo a las circunstancias individuales de la persona con discapacidad que se reflejaran en la extensión e intensidad del contenido de la medida y en su duración, debiendo el Juez pronunciarse sobre las mismas en la correspondiente sentencia que establezca la figura de apoyo que asegure la flexibilidad y adaptabilidad a las necesidades concretas de la persona con discapacidad, teniendo en los derechos y autonomía de ésta, la menor incidencia posible, respetándose en la medida que se pueda la autonomía, la voluntad y las preferencias de esa persona con discapacidad.
} 
AMUNÁTEGUI RODRÍGUEZ, C., "El protagonismo de la persona con discapacidad en el diseño y gestión del sistema de apoyo", en S. de Salas Murillo y M. V. Mayor del Hoyo (dir.), Claves para la adaptación del Ordenamiento jurídico privado a la Convención de Naciones Unidas en materia de discapacidad, Tirant lo Blanch, Valencia, 2019, pp. 125-163.

ARIJA SOUTULLO, C., "Algunas consideraciones sobre la reforma legal en materia de modificación judicial de la capacidad y de las medidas de protección a las personas con capacidad modificada, Estudios", en L. Díez-Picazo (Coord.), Homenaje al Prof. José Má. Miquel, Vol. I, Thomson Reuters- Aranzadi, Navarra, pp.387-408.

BARRIO GALLARDO, A., "La repercusión del artículo 12 de la Convención de Nueva York sobre el sistema tutelar español, Estudios”, en L. Díez-Picazo (Coord.), Homenaje al Prof. José $M^{a}$. Miquel, Thomson Reuters- Aranzadi, Navarra, pp. 465-485.

BERROCAL LANZAROT, A.I., "La curatela como institución de protección en el marco de la convención sobre los derechos de las personas con discapacidad", Revista Critica de Derecho Inmobiliario, $\mathrm{n}^{\mathrm{o}} 732$, 2012, pp. 2248-2297.

CAMPOY CERVERA, I., La recepción y aplicación en España de la Convención de Naciones Unidas sobre los Derechos de las Personas con discapacidad, Laborum, Murcia, 2017.

CARBONNIER, J., Droit Civil I, Les personnes. Incapacite, 17 ed., PUF, Themis, Paris, 2000.

CARRASCO PERERA, A., Discapacidad personal y estabilidad contractual. A propósito del Anteproyecto de Ley presentado por el Ministerio de Justicia para la reforma de la Legislación civil en materia de discapacidad. Publicaciones Jurídicas, Centro de Estudios de Consumo, octubre 2018. (http://centrodeestudiosdeconsumo.com/).

CUENCA GÓMEZ, P. "Grandes cuestiones pendientes en el ordenamiento español para acompasarse a los mandatos de la Convención. Libertad personal”, en E. Alcaín Martínez (dir.) y G. E. Álvarez Ramirez (coords.), La convención internacional sobre los Derechos de las personas con discapacidad. De los hechos a los derechos, Tirant lo Blanch, Valencia, pp. 132-142.

CUENCA GÓMEZ, P. "El sistema de apoyo en la toma de decisiones desde la Convención Internacional sobre los Derechos de las Personas con Discapacidad: principios generales, aspectos centrales e implementaciones en la legislación española", REDUR, nº 10, 2012, pp. 61-94.

CUENCA GÓMEZ, P. Estudios sobre el impacto de la Convención Internacional sobre los Derechos de las personas con discapacidad en el Ordenamiento Jurídico español, Dykinson, Madrid, 2010.

DE ASIS ROIG, R., BARRANCO AVILÉS, M. C., CUENCA GOMÉZ, P. y PALACIOS RIZZO, A., "Algunas reflexiones generales sobre el impacto de la Convención Internacional de los Derechos de las personas con Discapacidad en el Derecho español”, en P. Cuenca Gómez (Ed.), Estudios sobre el impacto de la Convención Internacional sobre los derechos de las personas con discapacidad en el Ordenamiento Jurídico español Dykinson, Madrid, 2010, p. 28 y ss.

DE CASTRO, F., Derecho civil de España, Tomo II (Derecho de la Persona), Instituto de Estudios Políticos, Madrid, 1952.

DE CASTRO, F., Derecho Civil de España, I, Instituto de Estudios Políticos, Madrid, 1955.

DE CASTRO, F., Derecho Civil de España II, Instituto de Estudios Políticos, Madrid, 1964. 
DE PABLO CONTRERAS, P. “Comentario de la Sentencia del Tribunal Supremo 282/2009, de 29 de abril de 2009, (RJ 2009, 2901). La incapacitación en el marco de la Convención sobre los derechos de las personas con discapacidad", en M. Yzquierdo Tolsada (dir.), Comentarios a las Sentencias de unificación de doctrina (Civil y Mercantil), vol. 3, 2009, Dykinson, Madrid, 2010, pp. 555-590.

DÍAZ ALABART, S., “Actuación de las personas con discapacidad en el ámbito personal y familiar: el derecho a su libertad personal", en M. Pereña Vicente (dir.), La voluntad de la persona protegida. Oportunidades riesgos y salvaguardias, Dykinson, Madrid, 2019, pp. 163-197.

DÍEZ-PICAZO y GULLÓN, A., Sistema de Derecho Civil, Vol. I, 6a ed., Tecnos, Madrid, 1988.

DÍEZ-PICAZO, L., Nota preliminar, en L. Díez-Picazo y M. de la Cámara Álvarez, La doctrina del enriquecimiento injustificado, Civitas, Madrid, 1987.

DOMÍNGUEZ LUELMO, A. y TORRES GARCÍA, T., "La incapacitación”, en M. C. Gete-Alonso y Calera (dir.), Tratado de Derecho de la persona física, Vol. II, Aranzadi, Navarra, 2013, pp. 53121.

ECHEVARRÍA DE RADA, T. “Autonomía de la voluntad y exigencia de forma en determinados instrumentos de protección de personas especialmente vulnerables", Aranzadi civil-mercantil, Revista doctrinal, vol. 2, nº 7, 2013, pp. 67-109.

ENGISCH, K., Introducción al pensamiento jurídico, Trad. esp. y adaptación al Código Civil español, Guadarrama, Madrid, 1967.

ESCRIBANO TORTEJADA, P. El patrimonio protegido de la persona con discapacidad, Tirant lo Blanch, Valencia, 2012.

FERNÁNDEZ DE BUJAN, A., “Capacidad, discapacidad. Incapacitación: Modificación judicial de la capacidad”, Revista Jurídica de la Universidad Autónoma de Madrid, nº 23, 2011, pp. 53-81.

FERNÁNDEZ DE BUJAN, A., "Capacidad, discapacidad, incapacitación: Modificación judicial de la capacidad”, RDUNED. Revista de Derecho UNED, n 9, 2011, pp. 83- 92.

FERNÁNDEZ DE BUJAN, A., “Capacidad, discapacidad, incapacitación: Modificación judicial de la capacidad”, Revista General de Derecho Romano, n’ 17, 2011.

FERNÁNDEZ DE BUJAN, A., "Convención de 2006 sobre los derechos de las personas con discapacidad y proceso de incapacitación", ICADE: Revista de la Facultad de Derecho, no 83-84, 2, 2011, pp. 119-155.

FERNÁNDEZ DE BUJAN, A., "Capítulo VII. Incapacitación y discapacidad”, en G. Díez-Picazo Giménez (Coord.), Derecho de Familia, 2012, pp. 1903-1954.

GARCÍA CANTERO, G., "Reflexiones sobre la mejor regulación jurídico-privada de la discapacidad", Revista Jurídica del Notariado, 82, 2012, pp. 207-228.

GARCÍA CANTERO, G., "Reflexiones sobre la mejor regulación jurídico-privada de la discapacidad", en S. Salas Murillo (Coord.), Los mecanismos de guarda legal de las personas con discapacidad tras la Convención de las Naciones Unidas, Dykinson, Madrid, 2013, pp. 41-56.

GARCÍA PONS, A., "El artículo 12 de la Convención de Nueva York de 2006 sobre los Derechos de las Personas con Discapacidad y su impacto en el Derecho Civil de los Estados signatarios: el caso de España", Anuario de Derecho Civil, vol. 66, n 1, 2013, p. 59-147. 
GARCÍA PONS, A., Las personas con discapacidad en el Ordenamiento Jurídico español, Ramón Areces, Madrid, 2008

GARCÍA RUBIO, M. P., “Algunas propuestas de reforma del Código Civil como consecuencia del nuevo modelo de discapacidad. En especial en materia de sucesiones, contratos y responsabilidad civil", Revista de Derecho Civil, vol. 5, no 3, 2018, pp. 173-197.

GARCÍA RUBIO, M. P., “La necesaria y urgente adaptación del Código Civil español al artículo 12 de la Convención de Nueva York sobre los derechos de las personas con discapacidad", Anales de la Academia Matritense del Notariado, vol. 58, no 1, 2018, pp.143-192.

GETE-ALONSO Y CALERA, M. C., "Capacidad de obrar y ejercicio de los derechos de la personalidad de la persona con discapacidad”, en M. C. García Garnica (dir.), Estudios sobre Dependencia y Discapacidad, Aranzadi, Navarra, 2011, pp. 41-98.

GUILARTE MARTÍN-CALERO, C., "La reinterpretación jurisprudencial de los sistemas de protección a la luz de la Convención de Nueva York: el nuevo paradigma de la Sala Primera", en C. Guilarte Martín-Calero (dir.), Estudios y comentarios jurisprudenciales sobre discapacidad, Aranzadi, Navarra, 2016, pp. 59-107.

GUILARTE MARTÍN-CALERO, C., “La contribución de la jurisprudencia del Tribunal Supremo al diseño del nuevo sistema de protección previsto en el anteproyecto de Ley por la que se reforma la legislación civil y procesal en materia de discapacidad de 21 de septiembre de 2018”, en S. de Salas Murillo y M. V. Mayor del Hoyo (dir.), Claves para la adaptación del Ordenamiento jurídico privado a la Convención de Naciones Unidas en materia de discapacidad, Tirant lo Blanch, Valencia, 2019, 361-398.

GORDILLO CAÑAS, A., Capacidad, incapacidades y estabilidad de los contratos, Tecnos, Madrid, 1986.

GULLÓN BALLESTEROS, A., "Capacidad jurídica y capacidad de obrar", Estudios de Derecho judicial., no 22, 1999, pp. 11-22.

GUTIERREZ GUTIÉRREZ, I., "La dignidad quebrada", Teoría y realidad constitucional, no 14, 2004, pp. 331-343.

GUTIÉRREZ GUTIÉRREZ, I., Dignidad de la persona y derechos fundamentales, Marcial Pons, Madrid, 2005.

HERNÁNDEZ-GIL, A., El concepto de Derecho Civil, Revista de Derecho Privado, Madrid, 1943.

KANT, E., Introducción a la Teoría del Derecho (Introducción a la Metafísica de las Costumbres y a la Teoría del Derecho), Trad. e introducción de F. González Vicen, IEP, Madrid, 1954.

LEGERÉN MOLINA, A., "La relevancia de la voluntad de la persona con discapacidad en la gestión de apoyos", en S. de Salas Murillo y M. V. Mayor del Hoyo (dir.), Claves para la adaptación del Ordenamiento jurídico privado a la Convención de Naciones Unidas en materia de discapacidad, Tirant lo Blanch, Valencia, 2019, pp.165-211.

LEGERÉN MOLINA, A., La tutela del incapaz ejercitada por la entidad pública. Estudio del art. 239.3 del Código Civil, Centro de Estudios Ramón Areces, Madrid, 2012.

LEGERÉN MOLINA, A., y ROVIRA SUEIRO, M. E., Instrumentos de protección de la discapacidad a la luz de la Convención de Naciones Unidas, Thomson-Reuters-Aranzadi, Cizur Menor, 2015.

MARTÍNEZ DE AGUIRRE ALDAZ, C., El tratamiento jurídico de la discapacidad psíquica: reflexiones para una reforma legal, Aranzadi, Navarra, 2014. 
MARTÍNEZ DE AGUIRRE ALDAZ, C., "Curatela y representación: cinco tesis heterodoxas y un estrambote”, en S. de Salas Murillo y Mayor del Hoyo, M. V. (dir.), Claves para la adaptación del ordenamiento jurídico privado a la Convención de Naciones Unidas en materia de discapacidad, Tirant lo. Blanch, Valencia, 2019, pp. 253-270.

MARTÍNEZ DE AGUIRRE ALDAZ, C., "El tratamiento jurídico de la discapacidad mental o intelectual tras la Convención sobres los Derechos de las personas con discapacidad", en S. Salas Murillo (coord.), Los mecanismos de guarda legal de las personas con discapacidad tras la Convención de Naciones Unidas, Dykinson, Madrid, 2013, pp. 15-40.

MARTÍNEZ DIE, R., La protección jurídica de discapacitados, incapaces y personas en situaciones especiales, Civitas, Madrid, 2000.

MAYOR FERNÁNDEZ, D., "La reforma de la protección jurídica civil de la discapacidad y la convención de Nueva York de 13 de diciembre de 2006", Boletín del Ministerio de Justicia, Año 65, no 2133, 2011, pp. 10-37.

MAYOR DEL HOYO, M. V., El nuevo modelo de protección de las personas con discapacidad. Desamparo, intervención de las Entidades Públicas y acogimiento familiar, Thomson Reuters-Aranzadi, Cizur Menor, 2013.

PALACIOS BARREIROS, A., El modelo social de discapacidad: orígenes, caracterización y plasmación en la Convención Internacional sobre los Derechos de las personas con discapacidad, Cinca /Caja Madrid, Madrid, 2008. (Colección Cermi.es, n $n^{\circ}$ 36).

PARRA LUCAN, M. A., La voluntad y el interés de las personas vulnerables. Modelos para la toma de decisión en asuntos personales, Ramón Areces, Madrid, 2015.

PAU PEDRÓN, A., "El principio de igualdad y el principio de cuidado, con especial atención a la discapacidad", Revista de Derecho civil, vol. 7, nº 1, 2020, pp. 3-29.

PAU PEDRÓN, A., "De la incapacitación al apoyo: el nuevo régimen de la discapacidad intelectual en el Código Civil”, Revista de Derecho Civil, vol. 5, nº 3, 2018, pp. 5-28.

PALLARÉS NEILA, J., "La revisión de las Sentencias dictadas en el nuevo procedimiento de provisión de apoyos", Revista de Derecho Civil, vol. 5, n 3, 2018, pp. 153-171.

PEREÑA VICENTE, M. "La transformación de la guarda de hecho en el anteproyecto de Ley", Revista de Derecho Civil, vol. 5, n 3, 2018, pp. 61-83.

PEREÑA VICENTE, M. "El incapacitado ante la nueva protección jurídica del discapacitado", Actualidad Civil, no 15, 2004, pp. 1758-1772.

PEREÑA VICENTE, M. "Derechos fundamentales y capacidad jurídica. Claves para una propuesta de reforma legislativa", Revista de Derecho Privado, no 4, 2016, pp. 3-40.

PEREÑA VICENTE, M. "La convención de Naciones Unidas y la nueva visión de la capacidad jurídica”, en J. Pérez de Vargas Muñoz y M. Pereña Vicente (coord.), La encrucijada de la incapacitación y la discapacidad, La Ley, Las Rozas, Madrid, 2011, pp. 195-208.

PÉREZ BUENO, L.C. y ÁLVAREZ RAMIREZ, G., "Los principios", en L. de Lorenzo García y L.C. Pérez Bueno (dir.), Fundamentos del Derecho de la Discapacidad, Aranzadi, Navarra, 2020, pp. 139-178. 
PÉREZ BUENO, L.C. y ÁLVAREZ RAMIREZ, G., "De las personas", en L. de Lorenzo García y L.C. Pérez Bueno (dir.), Fundamentos del Derecho de la Discapacidad, Aranzadi, Navarra, 2020, pp. 255-271.

PÉREZ DE ONTIVEROS BAQUERO, M. C., "La convención internacional sobre los derechos de las personas con discapacidad y el sistema español de modificación de la capacidad de obrar", Derecho Privado y Constitución, no 23, 2009, pp. 335-368.

PÉREZ DE ONTIVEROS BAQUERO, M. C., "Sentencia de 29 de abril de 2009: Incapacitación judicial. Interpretación de los artículos 199 y 200 del Código Civil y demás legislación vigente en materia de incapacitación a efectos de acreditar su adecuación a la Convención Internacional sobre los derechos de las personas con, discapacidad, ratificada por España", Cuadernos Civitas de Jurisprudencia Civil, $\mathrm{n}^{\circ}$ 82, 2010, pp. 317-350.

RAMS ALBESA, J., "Hombre y persona. Personalidad. Capacidad e incapacidad. Discapacidad y vejez (Reflexiones sobre estos conceptos jurídicos esenciales, de ordinario tratados como lugares comunes)", Revista Crítica de Derecho Inmobiliario, 2011, n 723, pp. 211-296.

RECOVER BALBOA, T. "Hacia la reforma del Código Civil y la Ley de Enjuiciamiento Civil en materia de discapacidad”, en M. C. García Garnica (dir.), Nuevas perspectivas del tratamiento jurídico de la discapacidad y la dependencia, Dykinson, Madrid, 2017, pp. 19-30.

RIBOT IGUALADA, J., "La nueva 'curatela': diferencia con el sistema anterior y perspectivas de funcionamiento", en S. de Salas Murillo y M. V. Mayor del Hoyo (dir.), Claves para la adaptación del Ordenamiento jurídico privado a la Convención de Naciones Unidas en materia de discapacidad, Tirant lo Blanch, Valencia, 2019, pp. 215-252.

RIVERA ÁLVAREZ, J. M., "Notas sobre el apoyo a la autodeterminación de la persona incapacitada en el Código Civil a partir de la Convención de las Naciones Unidas sobre derechos de las personas con discapacidad", en J. Pérez de Vargas Muñoz (dir.) y M. Pereña Vicente (coord.), Encrucijada de la incapacitación y la discapacidad, La Ley, Madrid, 2011, pp. 347-372.

RODRIGUEZ ESCUDERO, M. V., "La incapacitación y el respeto a los derechos de las personas discapacitadas: el interés de la persona protegida", en J. Pérez de Vargas Muñoz (dir.) y M. Pereña Vicente (coord.), Encrucijada de la incapacitación y la discapacidad, La Ley, Las Rozas, Madrid, 2011, pp. 373-392.

ROVIRA SUEIRO, M. E., "La convención de las Naciones Unidas sobre los derechos de las personas con discapacidad: su impacto en el ordenamiento jurídico español”, en M. E. Rovira-Sueiro, y A. Legerén-Molina (coord.), Instrumentos de Protección de la discapacidad a la luz de la Convención de Naciones Unidas, Aranzadi, Navarra, 2016, pp. 15-61.

SALAS MURILLO, S., "Significado jurídico del 'apoyo en el ejercicio de la capacidad jurídica' de las personas con discapacidad: presente tras diez años de Convención”, Revista doctrinal Aranz̧adi civil-mercantil, $\mathrm{n}^{\circ}$ 5, 2018, pp. 1-33.

SÁNCHEZ DE LA TORRE, A. "Capacidad, personalidad jurídica, derecho subjetivo, responsabilidad", en A. Sánchez de la Torre, Fundamentos de conocimiento jurídico. La capacidad jurídica, Dykinson, Madrid, 2005, pp. 17-24.

SÁNCHEZ DE LA TORRE, A. "Discapacidad, condición humana y dignidad humana", en A. Sánchez de la Torre, Fundamentos de conocimiento jurídico: La capacidad jurídica, Dykinson, Madrid, 2005, pp. 375-386. 
SANTOS URBANEJA, F., "Crónica de Previstonia. A propósito de los efectos en el Código Civil de la Convención de las Naciones unidas sobre Derechos de las Personas con Discapacidad; en Conclusiones de las Jomadas Fiscales especializadas en la protección de la persona con discapacidad y tutelas, Madrid, 2009, pp. 25-26; LexFamily.es, Revista digital de Derecho de familia, 10; y en (http://www.fiscal.es).

SEOANE RODRÍGUEZ, J. A., "La Convención de la ONU sobre los derechos de la persona con discapacidad: perspectiva jurídica", Siglo Cero. Revista Española sobre discapacidad intelectual., vol. $42, n^{\circ} 237,2011$, pp. 21-32.

SERRANO GARCÍA, I., "Discapacidad e incapacidad en la Ley 41/2003 de 18 de noviembre", Revista Jurídica del Notariado, $\mathrm{n}^{\circ}$ 52, 2004, pp. 231-274.

SERRANO GARCÍA, I., Autotutela. El artículo 223-II del Código Civily la Convención de Nueva York sobre los derechos de las personas con discapacidad de 2006, Tirant lo Blanch, Valencia, 2012.

TORRES COSTAS, M. E., La capacidad jurídica a la luz del artículo 12 de la Convención de las Naciones Unidas sobre los Derechos de las personas con discapacidad, Agencia Estatal Boletín Oficial del Estado, Madrid, 2020.

TORRES GARCÍA, T. F., "La persona y el Derecho civil”, en D. Jiménez Liébana (coord.), Estudios de Derecho civil en homenaje al Profesor José Gonález García, Aranzadi Thomson-Reuters, Navarra, 2013, pp. 163-173.

TORRES GARCÍA, T. F., "Efectos de la incapacitación”, en M. Gete-Alonso y Calera (dir.), Tratado de Derecho de la persona física, Vol. II, Aranzadi, Navarra, 2013, pp. 123-171.

TORRES GARCÍA, T. F., "La incapacitación: Don Federico de Castro al momento actual”, en L. Díez Picazo (dir.), Glosas sobre Federico de Castro, Aranzadi, Navarra, 2015, pp. 398-408.

VAlLET De GOYTISOLO, J. B., Panorama del Derecho Civil, Bosch, Barcelona, 1963.

VARGAS CABRERA, B., "Aspectos civiles y procesales de la discapacidad”, en I. Serrano García (coord.), La protección jurídica del discapacitado, Tirant lo Blanch, Valencia, 2003, pp. 121-132.

VERDERA IZQUIERDO, B., "La modificación y reintegración de la capacidad de obrar. El principio de no discriminación", en J. Pérez de Vargas Muñoz (dir.) y M. Pereña Vicente (coord.), Encrucijada de la incapacitación y la discapacidad, vol. 2, La Ley, Madrid, 2011, pp. 415428.

VIVAS TESÓN, I., "Más allá de la capacidad de entender y querer: algunas consideraciones de lege ferenda acerca de la protección de las personas diversamente capaces", en M. Cuena Casas, L. Anguita Villanueva y J. Ortega Domenech (coord.), Estudios de Derecho civil en homenaje al Prof. Joaquin Rams Albesa, Dykinson, Madrid, 2013, pp. 1655-1673.

VIVAS TESÓN, I., "El ejercicio de los derechos de personalidad de la persona con discapacidad", en S. de Salas Murillo y M. V. Mayor del Hoyo (dir.), Claves para la adaptación del Ordenamiento jurídico privado a la Convención de Naciones Unidas en materia de discapacidad, Tirant Lo Blanch, Valencia, 2019, pp. 409-443. 